\title{
Article \\ Bearing Capacity and Failure Mode of a Light-Steel Tubular K-joint Connected by a Novel U-shape Connector
}

\author{
Xiaoping Wang ${ }^{1}$, Xun Yuan ${ }^{1}$, Hui Zeng ${ }^{1}$, Tao $\mathrm{Li}^{1, * \mathbb{C}}$, Yang Liang ${ }^{2}$, Xiaoming Gao ${ }^{3}$ and Yinquan $\mathrm{Yu}^{3}$ \\ 1 School of Civil Engineering and Architecture, Wuhan University of Technology, Wuhan 430070, China; \\ whut_wangxp@whut.edu.cn (X.W.); gfyuanxun@163.com (X.Y.); zenghui9711@163.com (H.Z.) \\ 2 Center of Science and Technology \& Industrialization Development, Ministry of Housing and Urban-Rural \\ Development, Beijing 100835, China; pgtg4249@163.com \\ 3 China Institute of Building Standard Design \& Research, Beijing 100048, China; gaoxm2009@126.com (X.G.); \\ yuyq@cbs.com.cn (Y.Y.) \\ * Correspondence: scealitao@whut.edu.cn
}

Citation: Wang, $X . ;$ Yuan, X.; Zeng,

H.; Li, T.; Liang, Y.; Gao, X.; Yu, Y.

Bearing Capacity and Failure Mode of a Light-Steel Tubular K-joint Connected by a Novel U-shape Connector. Appl. Sci. 2021, 11, 8587. https://doi.org/10.3390/app11188587

Academic Editor: Jong Wan Hu

Received: 3 August 2021

Accepted: 13 September 2021

Published: 15 September 2021

Publisher's Note: MDPI stays neutral with regard to jurisdictional claims in published maps and institutional affiliations.

Copyright: () 2021 by the authors. Licensee MDPI, Basel, Switzerland. This article is an open access article distributed under the terms and conditions of the Creative Commons Attribution (CC BY) license (https:// creativecommons.org/licenses/by/ $4.0 /)$
Abstract: This study aims to investigate the ultimate bearing capacity of a novel tubular K-joint used for light-steel structures consisting of thin-walled square hollow section members, a U-shape connector and self-drilling screws, and the effect of three patterns of stamping indentation fabricated on the U-shape connector on the ultimate bearing capacity of the proposed K-joint. Firstly, a total of $12 \mathrm{~K}$-joint specimens were tested to failure under monotonic brace axial compressive loading. Secondly, failure mode and the ultimate bearing capacity of each specimen were investigated and analyzed. Finally, finite element analyses were carried out to study the effect of three key parameters, including chord axial stress ratio, half width-to-thickness ratio of the chord and brace-to-chord wall thickness ratio, on the ultimate bearing capacity of the proposed K-joints using the recommended U-shape connector. It was found that failure mode of the proposed K-joint is governed by both the deformation of the U-shape connector and the chord local plastification. Besides, the K-joint specimen using a U-shape connector with the strip stamping grooves in the horizontal direction generally has a higher bearing capacity and a much smaller connector deformation. Similar to the welded tubular joints, chord axial stresses may also significantly reduce the ultimate bearing capacity of the proposed K-joint.

Keywords: light-steel structure; novel tubular K-joint; U-shape connector; pattern of stamping indentation; chord axial stress

\section{Introduction}

Tubular structure has been widely used in many buildings such as railway stations, stadiums, airports, bridges, jack-up offshore platforms, coal sheds and farm buildings due to its high bearing capacity and low weight [1]. Generally, a tubular structure is constructed by connecting different hollow section members. Therefore, connection between different hollow section members is crucial. The thickness of hollow section members used in heavyload tubular structures is relatively thick, and thus, they are frequently welded together directly in reality. However, for light-steel tubular structures, thickness of the hollow section members is generally in between 0.6 and $2 \mathrm{~mm}$, and thus, it is not preferred to use welding to connect them due to welding defects that frequently occur, such as welding penetration. Besides, welding is very time consuming and also requires high welding skill. Traditionally, screws, rivets and bolts are preferred to connect thin-walled steel sections used in light-steel structures [2-7] and the ultimate bearing capacity of the connection is one of the main concerns in engineering practice.

Many researchers have studied the bearing capacity, joint stiffness and failure mode of different connections of light-steel structures. For instance, Zaharia and Dubina [8] investigated the joint stiffness of bolted single-lap joints and cold-formed steel (CFS) 
trusses by conducting tests. They also proposed a theoretical model for predicting joint stiffness. Öztürk and Pul [9] carried out tests and numerical analyses on a full-scale apex connection of CFS frames. The apex connection was fabricated by connecting two CFS back-to-back double sigma rafter sections using a gusset apex plate and bolts. Similarly, Pouladi et al. [10] investigated the mechanical behavior of the eaves joint of CFS portal frames by carrying out finite element analyses (FEA). The eaves joint consisted of channel sections, screws and bolts. Far et al. [11] investigated the shear stiffness of thin-walled coldformed storage rack frames by carrying out experiments and numerical analyses. Channel sections of storage rack frames were connected using bolts. Yan et al. [4] carried out a comparative study on the mechanical behavior and construction characteristics of 96 CFS lap shear tests, including four types of connection using the self-piercing rivet, clinching, self-drilling screw and blind rivet, respectively. Song et al. [12] investigated the flexural behavior of CFS trusses assembled by using self-piercing rivets. Song et al. [13] also carried out experimental tests to investigate the structural behavior of CFS truss composite floors in which the truss is assembled using self-piercing rivets. Similarly, Wang et al. [14] carried out cyclic loading tests on CFS truss composite floors. The steel truss consisted of C-shaped steel sections connected by self-drilling screws. Roy et al. [15] carried out tests and FEA to investigate the effect of deployment patterns of self-drilling screws on the bearing capacity of high-strength CFS joints. Fahmy et al. [16] investigated the bearing capacity of five CFS connections assembled using two types of gusset plates and self-tapping screws. Mathieson et al. [17] conducted static and cyclic loading tests to investigate the failure mechanism and structural behavior of 26 CFS trusses. The CFS truss specimens were assembled by connecting C-shaped steel sections using a novel developed Howick rivet connector (HRC). Dizdar et al. [18] experimentally investigated the strength and stiffness of floor trusses consisting of CFS lipped channels. Phan et al. [19] investigated the bimoment effects on the load transfer in CFS bolted moment connections. The lipped channel chord and braces of the CFS trusses were connected using bolts. Zagórowska et al. [20] conducted static loading tests on five CFS joints with positive eccentricity. The chord of the five CFS joints was hat section and was connected with the C-shaped braces using bolts. Gan et al. [21] carried out tests and numerical analyses to investigate the effect of apex plate length and thickness on the CFS roof trusses. The apex plate and the C-shaped sections were connected using bolts. Güldür et al. [22] carried out experimental and numerical analyses on seven CFS floor trusses to investigate bearing capacity and structural behavior.

This study aims to propose and study a new joint for connecting thin-walled (thickness 0.6-2 mm) square hollow section (SHS) members to form a light-steel warren truss. Figure 1 illustrates the proposed joint in which two braces are connected to the chord using a patented U-shape connector and self-drilling screws. The U-shape connector is fabricated by stamping thin-walled hot galvanizing steel sheet. Screw holes are fabricated in the steel sheet before stamping it. The proposed joint has several superior advantages. Firstly, it is very easy to deliver all steel members to the construction site and assemble them together to form a warren truss using the proposed joint. No in-site welding work is required so that welding flaws can be avoided, and a high construction speed can be achieved. In addition, the pre-drilled screw holes of the U-shape connector can prevent sliding of the screw during screw drilling and expedite assembling speed; secondly, impairment to the SHS members is small as no cutting slot is required; finally, the U-shape connector can accommodate the flexibility of the brace diagonal angle from $30^{\circ}$ to $90^{\circ}$ and at least three self-drilling screws are guaranteed at each connecting surface of the brace. When designing a truss using the U-shape connector, pinned connection is assumed at the joint. After the axial forces of the braces are determined, the number of self-drilling screws can be calculated using the assumption that the screw swarm is under shear and takes all the force transferred from the brace. As the proposed joint has never been studied, it is necessary to investigate its bearing capacity and failure mode before it is used in reality. 


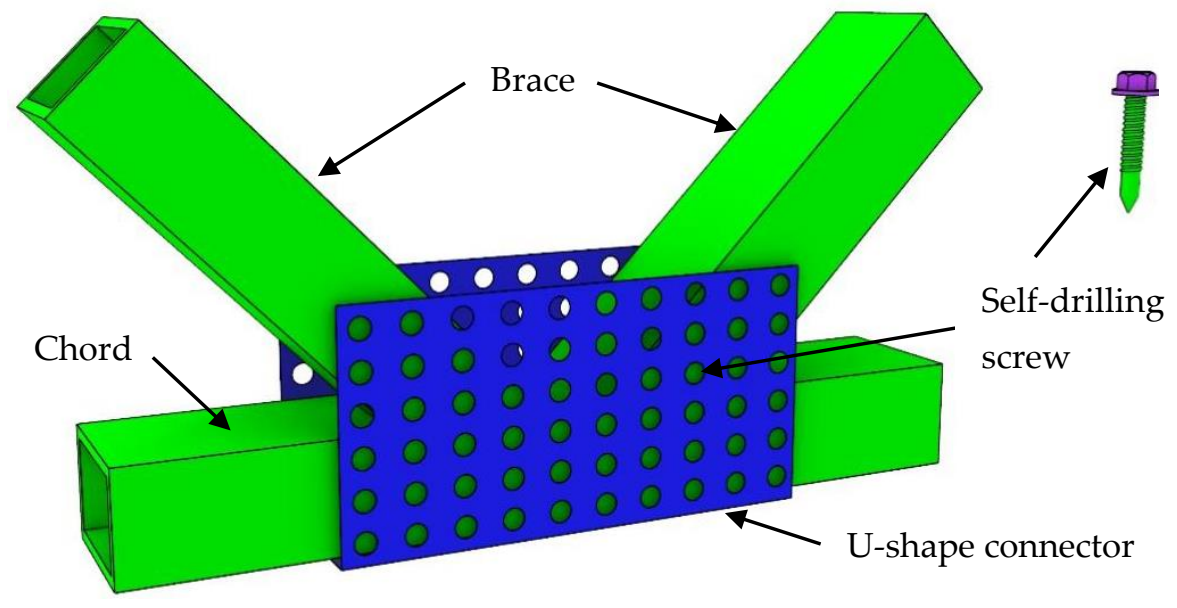

Figure 1. Proposed K-joint.

\section{Specimen Fabrication}

\subsection{U-shape Connectors and K-joint Specimens}

Four types of U-shape connectors have been used for $12 \mathrm{~K}$-joint specimens tested in this study, and they are named UPL, UPU, ULW and UTW, respectively. The U-shape connector named UPL is without stamping indentation while the other three have different patterns of stamping indentation as shown in Figure 2. For U-shape connector UPU, stamping pits are fabricated; for U-shape connectors ULW and UTW, strip stamping grooves are fabricated in the vertical and horizontal direction, respectively. By making a comparison among the testing results of specimens using different U-shape connectors, the most efficient one can be found. Figure 3 provides the geometries of four types of U-shape connectors and values of the parameters are summarized in Table 1.

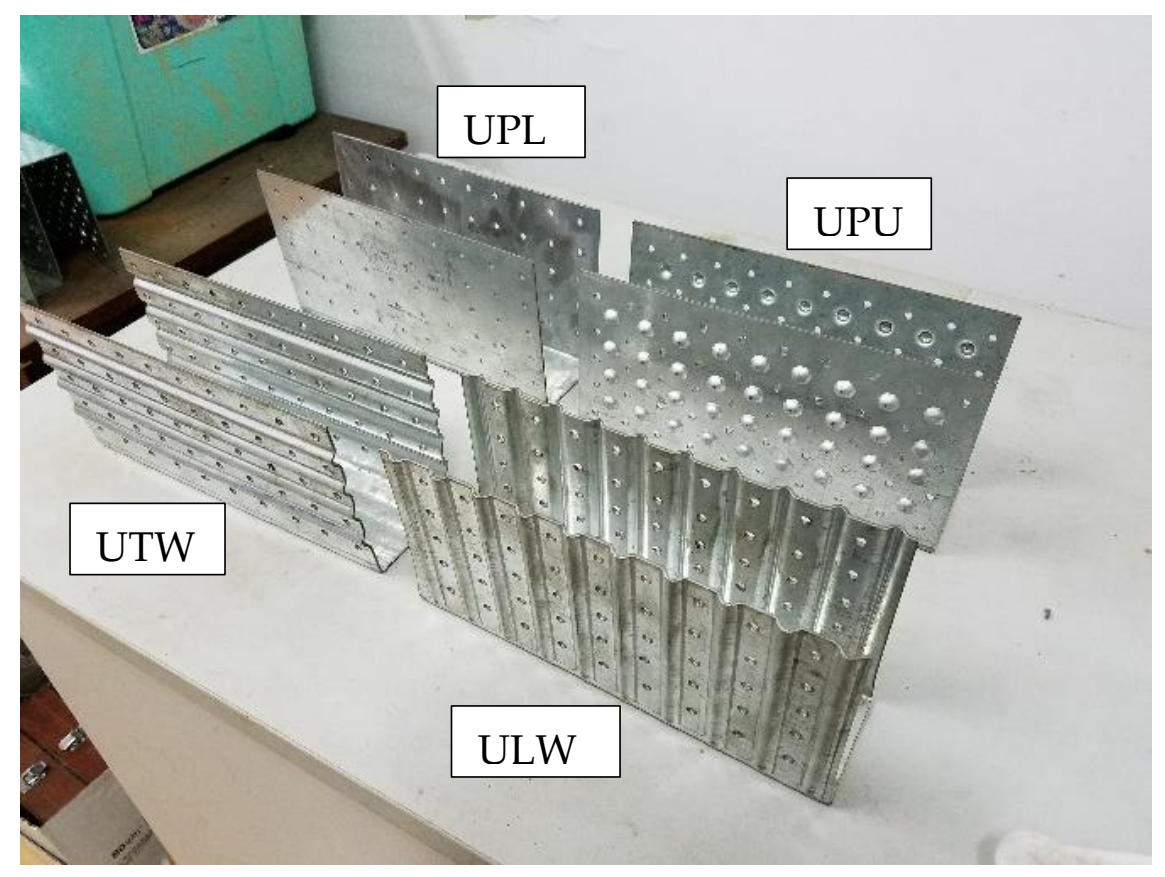

Figure 2. Four types of U-shape connector used. 


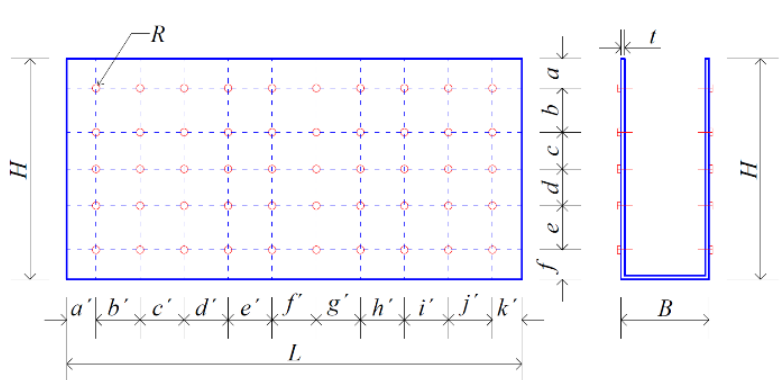

(a) UPL.

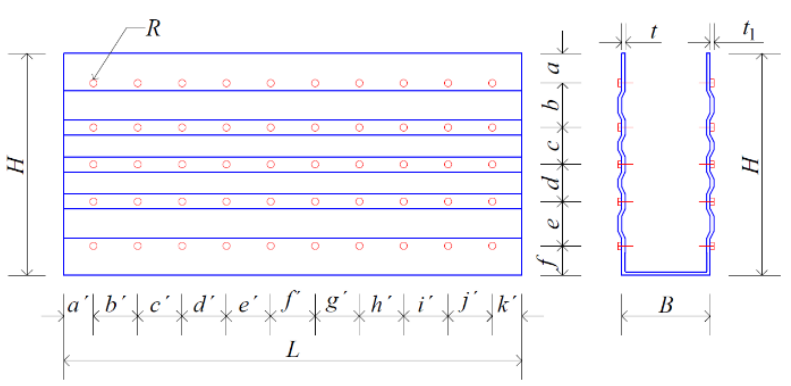

(c) UTW.

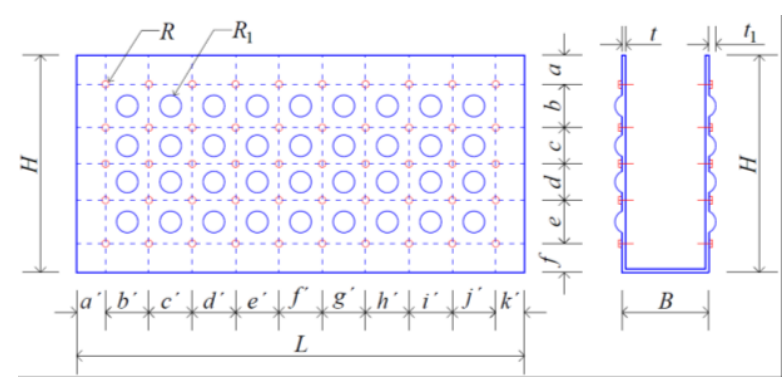

(b) UPU.

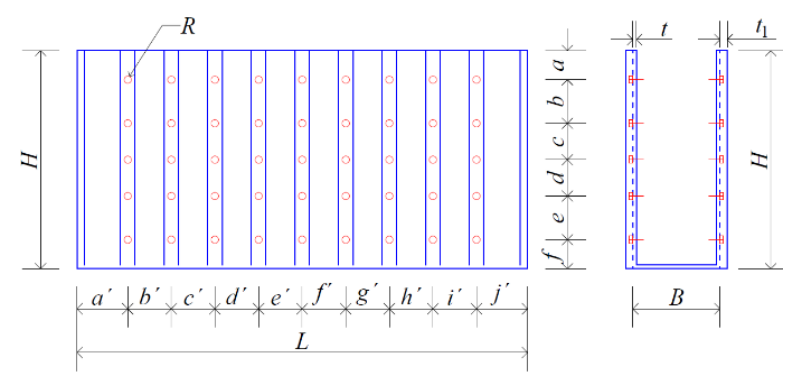

(d) ULW.

Figure 3. Dimensions of four U-shape connectors.

Table 1. Dimensions of U-shape connectors.

\begin{tabular}{|c|c|c|c|c|c|c|c|c|c|c|c|c|}
\hline No. & UPL1 & UPL2 & UPL3 & UPU1 & UPU2 & UPU3 & ULW1 & ULW2 & ULW3 & UTW1 & UTW2 & UTW3 \\
\hline$L$ & 243 & 238 & 241 & 242 & 241 & 242 & 239 & 242 & 241 & 240 & 240 & 242 \\
\hline$H$ & 123.50 & 124 & 123.50 & 123 & 123 & 123 & 119 & 120 & 120 & 123 & 124 & 124 \\
\hline$B$ & 64 & 65 & 63 & 66 & 66 & 64 & 66 & 64 & 63 & 65 & 66 & 65 \\
\hline$t$ & 1.74 & 1.71 & 1.75 & 1.75 & 1.73 & 1.73 & 1.75 & 1.77 & 1.76 & 1.75 & 1.75 & 1.74 \\
\hline$t_{1}$ & / & / & / & 6 & 6 & 6 & 6 & 6 & 6 & 6 & 6 & 6 \\
\hline$a$ & 13 & 12.50 & 12.50 & 16.50 & 17 & 16.50 & 9 & 10 & 10.50 & 13 & 12 & 13 \\
\hline$b$ & 23.50 & 23 & 23 & 25 & 25 & 25 & 23.50 & 23 & 23 & 24 & 24 & 24 \\
\hline$c$ & 21.50 & 21.50 & 22 & 20.50 & 21 & 21 & 22 & 22 & 21 & 20.50 & 20.50 & 20 \\
\hline$d$ & 22.50 & 22 & 22 & 21.50 & 21 & 21.50 & 23 & 22.50 & 22.50 & 20 & 20 & 20 \\
\hline$e$ & 23 & 22.50 & 22.50 & 24 & 24 & 24 & 23 & 23 & 23 & 23.50 & 23.50 & 23 \\
\hline$f$ & 22.50 & 23 & 22.5 & 16.50 & 16 & 16 & 21.50 & 21 & 21 & 23.50 & 24 & 24 \\
\hline$a^{\prime}$ & 14 & 12 & 14.50 & 14 & 12 & 15 & 12 & 13.50 & 12.50 & 23 & 24 & 25 \\
\hline$b^{\prime}$ & 25 & 25 & 25 & 23.50 & 23.50 & 23 & 25 & 25 & 25.50 & 24 & 24 & 23.50 \\
\hline$c^{\prime}$ & 24.50 & 24 & 24.50 & 24.50 & 24.50 & 24.50 & 24 & 24.50 & 24 & 24.50 & 24 & 23.50 \\
\hline$d^{\prime}$ & 25 & 24.50 & 25 & 24.50 & 24.50 & 24 & 24.50 & 25 & 24.50 & 23 & 23.50 & 23 \\
\hline$e^{\prime}$ & 24 & 23.50 & 24 & 24 & 24.50 & 24.50 & 23.50 & 24 & 24 & 25 & 23 & 24 \\
\hline$f^{\prime}$ & 24.50 & 24 & 24 & 24.50 & 24.50 & 24 & 24 & 23.50 & 23.50 & 24 & 23.50 & 24 \\
\hline$g^{\prime}$ & 25 & 24.50 & 24.50 & 25 & 25 & 25 & 24.50 & 25 & 25 & 24 & 23.50 & 24 \\
\hline$h^{\prime}$ & 25 & 24.50 & 24 & 24.50 & 24.50 & 24.50 & 25 & 25 & 25 & 24 & 23.50 & 23.50 \\
\hline$i^{\prime}$ & 23 & 23 & 23 & 24 & 24 & 24 & 22 & 23 & 23 & 24 & 24 & 24 \\
\hline$j^{\prime}$ & 25 & 24.50 & 25 & 23 & 23 & 23 & 25 & 25 & 25 & 24 & 24.50 & 24.50 \\
\hline$k^{\prime}$ & 10.50 & 8 & 10 & 12.5 & 14 & 11 & 9.50 & 10.50 & 11 & / & / & / \\
\hline$R$ & 5 & 5 & 5 & 5 & 5 & 5 & 5 & 5 & 5 & 5 & 5 & 5 \\
\hline$R_{1}$ & / & / & / & 12 & 12 & 12 & / & / & / & / & / & / \\
\hline
\end{tabular}

Note: unit in $\mathrm{mm}$.

A total of $12 \mathrm{~K}$-joint specimens were fabricated and divided into four groups according to the types of U-shape connector. Figure $4 \mathrm{a}$,d show the geometries of four typical K-joint specimens. Six self-drilling screws at each connecting surface of the brace are installed and highlighted in red in Figure 4a,d. Nominal thickness of all SHS members is $1.5 \mathrm{~mm}$ and diagonal angle of all braces is $45^{\circ}$. 


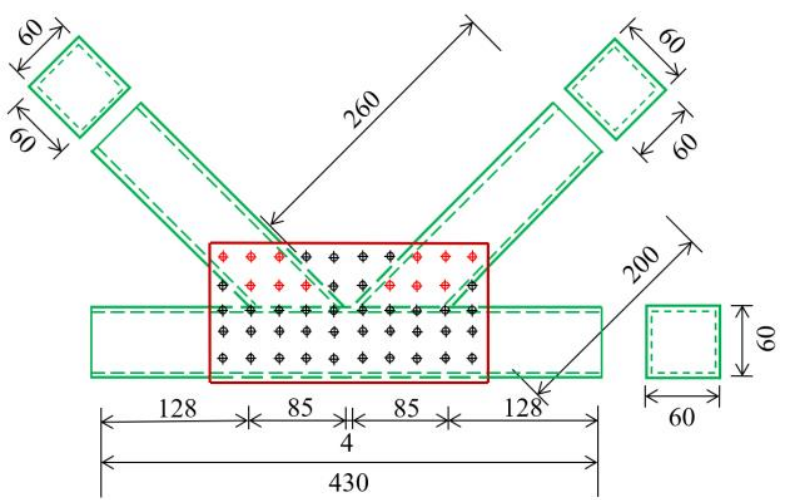

(a) Specimens in group 1.

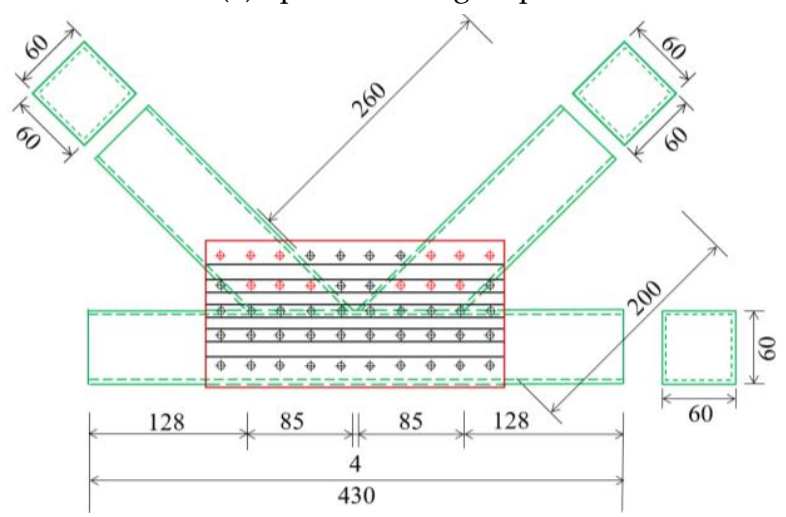

(c) Specimens in group 3.

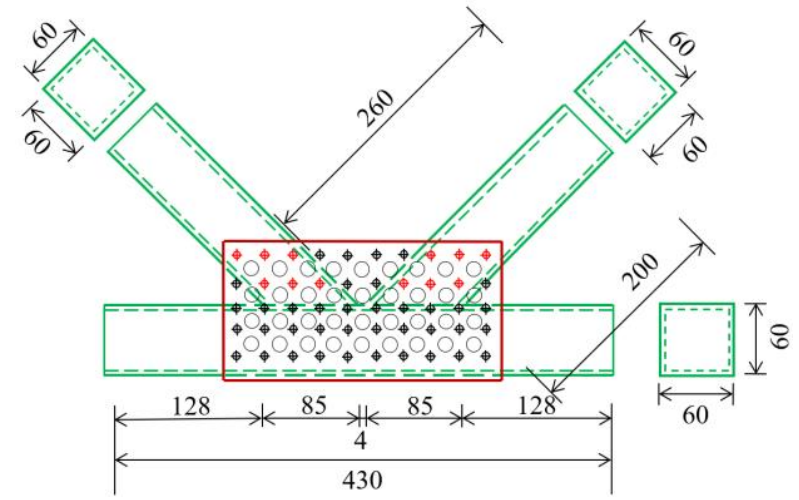

(b) Specimens in group 2.

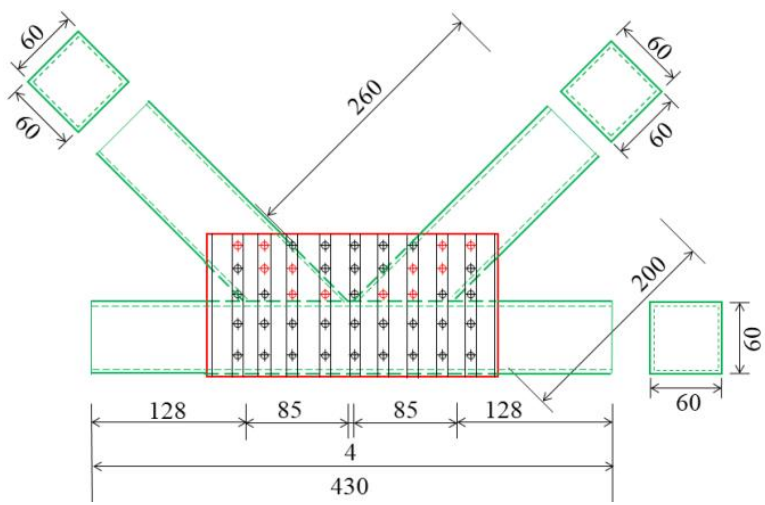

(d) Specimens in group 4.

Figure 4. Geometries of four typical K-joints (unit in $\mathrm{mm}$ ).

When assembling a K-joint specimen, firstly the U-shape connector is placed in the right position of the chord, and then it is connected to the chord using self-drilling screws as shown in Figure 5. Subsequently, the two braces are inserted into the U-shape connector and connected together using self-drilling screws. Six self-drilling screws are used for each K-joint specimen in this study. Figure 6 shows a completed K-joint specimen after self-drilling screws are installed.

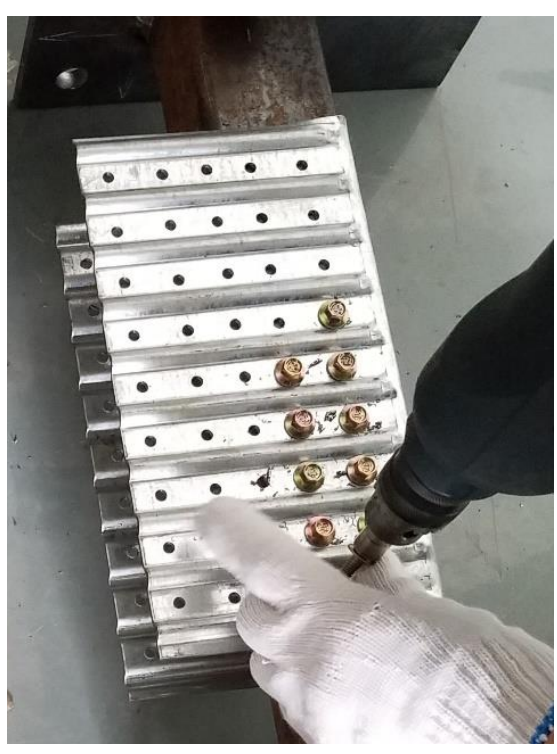

Figure 5. Connection between the U-shape connector and the chord. 


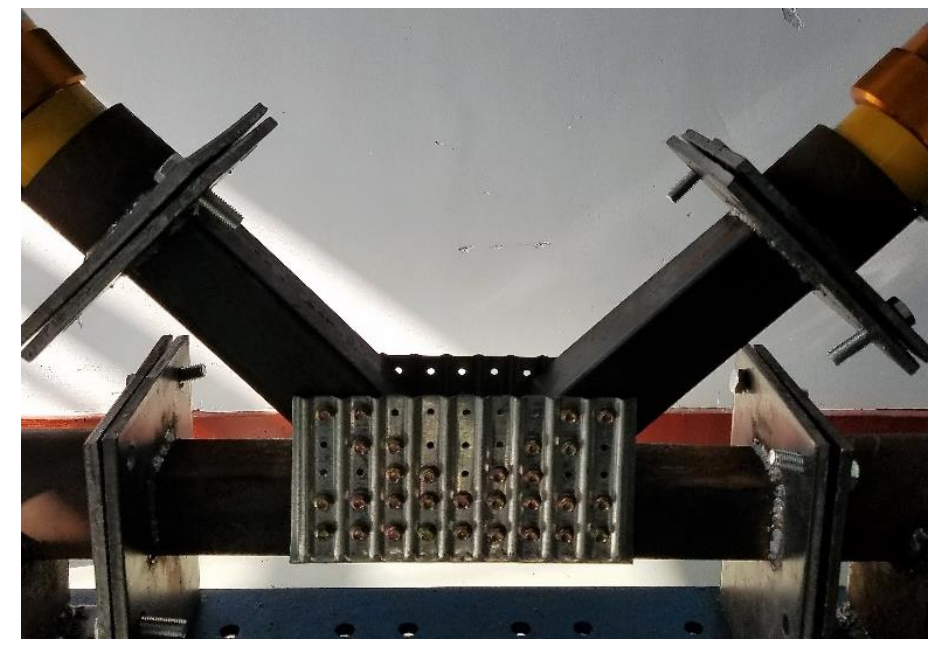

Figure 6. A completed K-joint specimen.

\subsection{Material Properties of Steel}

A total of 12 coupon test specimens have been fabricated and tested to failure. Figure 7 shows the dimensions of the coupon test specimens and Figure 8 shows the corresponding testing machine. Axial tensile loading is applied to each coupon specimen at a speed of $10 \mathrm{~N} / \mathrm{s}$. Material properties including elastic modulus, yield stress, ultimate stress and elongation rate of the 12 coupon test specimens are summarized in Table 2 . Names of specimens with ' $\mathrm{UP}^{\prime}$ ' and ' $\mathrm{XF}$ ' refer to the U-shape connectors and the SHS members, respectively.

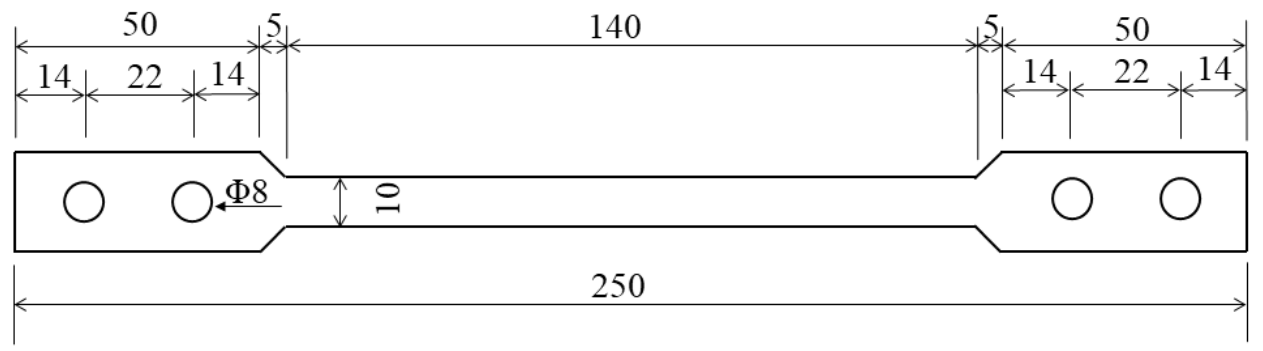

Figure 7. Dimensions of the coupon test specimen (unit in $\mathrm{mm}$ ).
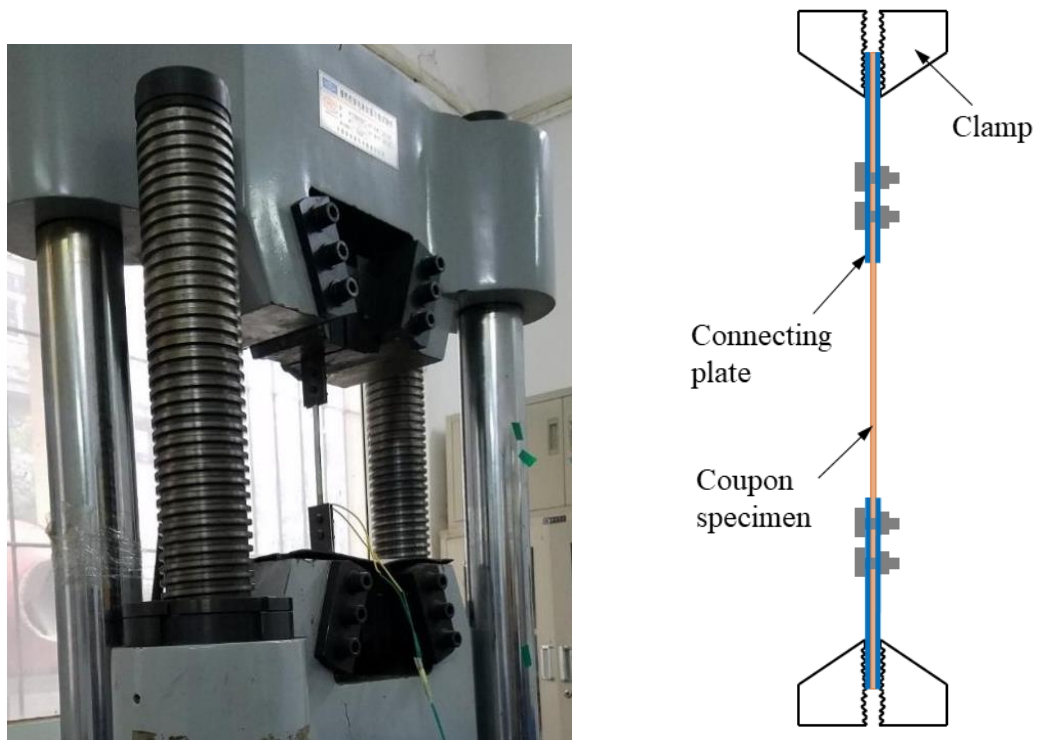

Figure 8. Setting up of the coupon test. 
Table 2. Material properties of U-shape connectors and SHS members.

\begin{tabular}{cccccc}
\hline \multirow{2}{*}{ Specimen No. } & Thickness & $\begin{array}{c}\text { Elastic } \\
\text { Modulus }\end{array}$ & Yield Stress & $\begin{array}{c}\text { Ultimate } \\
\text { Stress }\end{array}$ & $\begin{array}{c}\text { Elongation } \\
\text { Rate (\%) }\end{array}$ \\
\cline { 2 - 6 } & $\mathbf{( m m )}$ & $\mathbf{( G P a )}$ & $\mathbf{( M P a )}$ & $\mathbf{( M P a )}$ & \\
\hline UP-1 & 1.79 & 172 & 280.10 & 372.67 & 27.10 \\
UP-2 & 1.78 & 180 & 275.46 & 402.83 & 27.30 \\
UP-3 & 1.79 & 176 & 286.52 & 355.56 & 31.80 \\
UP-4 & 1.79 & 175 & 273.20 & 380.33 & 32.70 \\
UP-5 & 1.79 & 182 & 290.14 & 376.57 & 25.10 \\
UP-6 & 1.79 & 175 & 274.32 & 386.23 & 3000 \\
XF-1 & 1.44 & 202 & 327.23 & 390.42 & 2300 \\
XF-2 & 1.47 & 216 & 350.20 & 360.56 & 2100 \\
XF-3 & 1.48 & 209 & 315.46 & 390.33 & 2300 \\
XF-4 & 1.50 & 194 & 344.87 & 400.01 & 2300 \\
XF-5 & 1.45 & 205 & 300.00 & 385.66 & 2200 \\
XF-6 & 1.50 & 210 & 331.97 & 380.45 & 2100 \\
\hline
\end{tabular}

\section{Testing Rig, Loading Scheme and Displacement Transducer Deployment}

\subsection{Testing Rig and Loading Scheme}

Figure 9 shows the testing rig of the K-joint specimen. Two ends of the specimen are bolted to two tubes fixed to the resisting frame. Two jacks attached to the resisting frame are connected to the two braces. The same axial compressive force is applied to two braces by using the manual oil pump shown in Figure 10. Force loading is applied to each specimen with an interval of $4 \mathrm{kN}$ before $50 \%$ of the design value (about $40 \mathrm{kN}$ ) is reached. Subsequently, loading interval is changed to $2 \mathrm{kN}$ till the end of the testing.

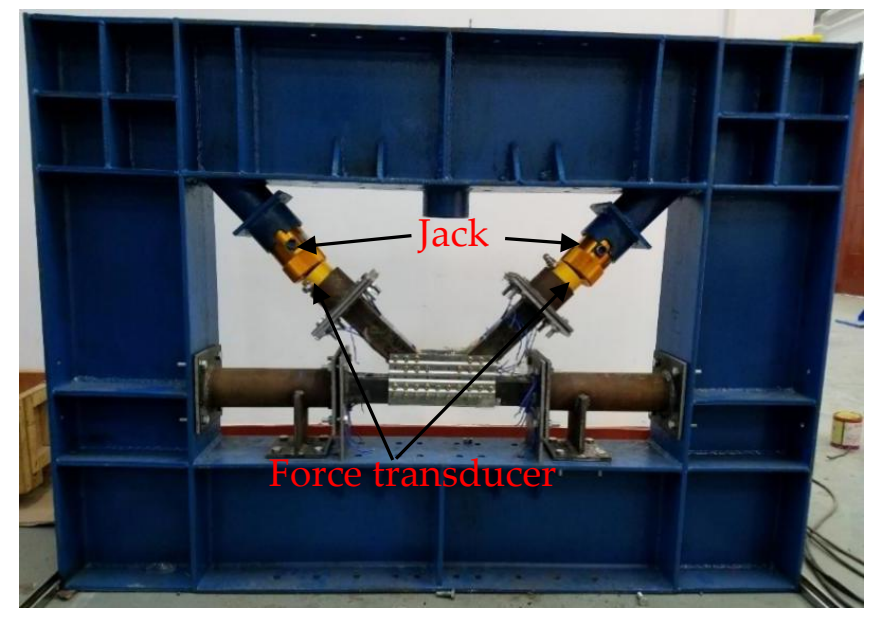

Figure 9. Testing rig of K-joint specimen.

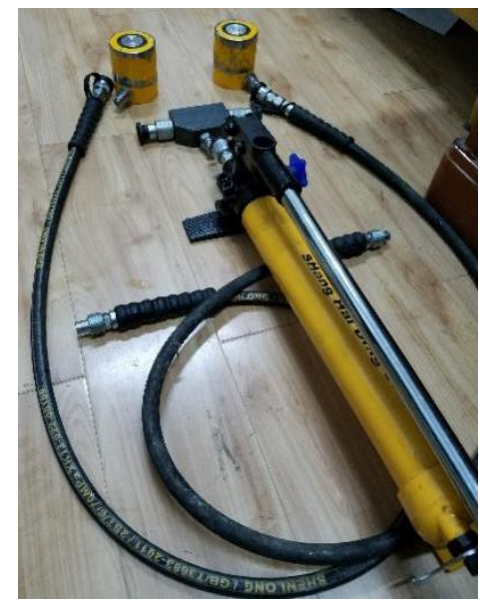

Figure 10. Manual oil pump. 


\subsection{Displacement Transducer Deployment}

A trial FEA shows that failure mode of the K-joint is severe deformation of the U-shape connector and chord local plastification. Therefore, eight displacement transducers (red points) were installed on each U-shape connector as shown in Figure 11. The displacement transducers were located either in the center of four screw holes or in the middle of two screw holes. Alphabet ' $\mathrm{A}$ ' and ' $\mathrm{B}$ ' indicate two opposite surfaces of the U-shape connector.

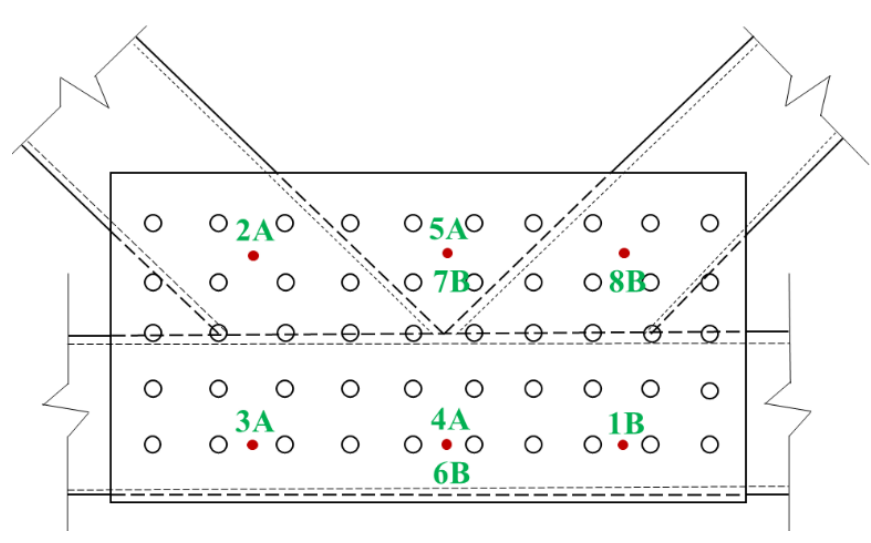

(a) Specimens in group 1.

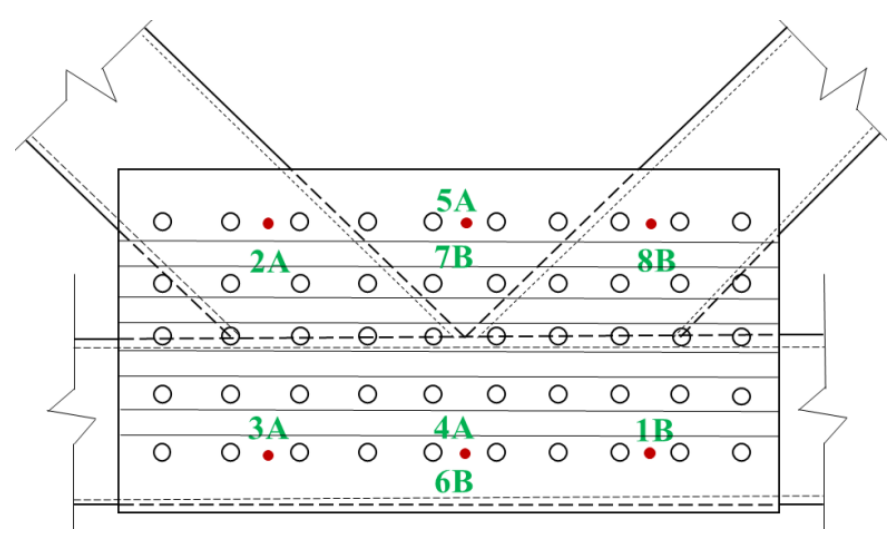

(c) Specimens in group 3 .

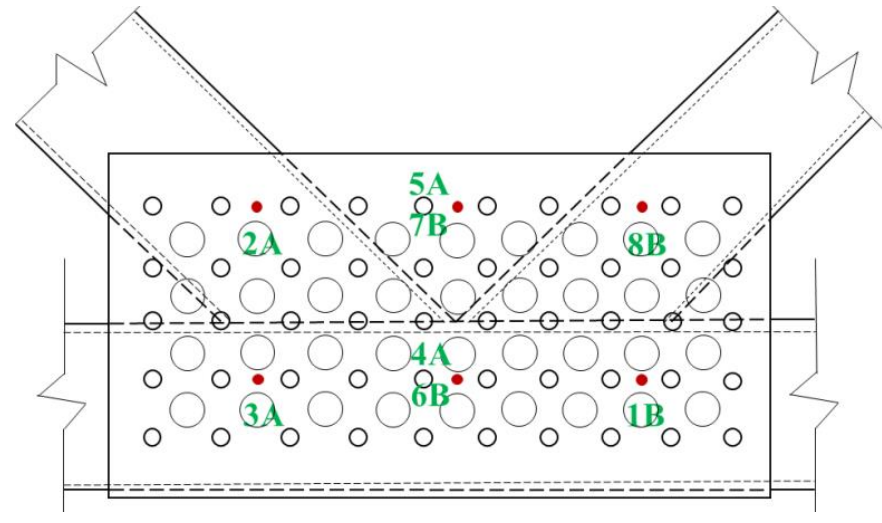

(b) Specimens in group 2.

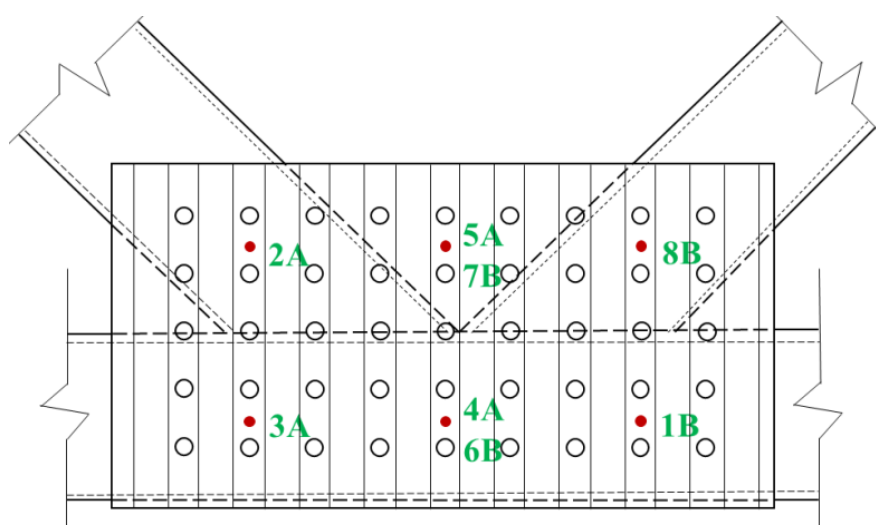

(d) Specimens in group 4 .

Figure 11. Deployment of displacement transducers of the K-joint specimen.

\section{Experimental Results}

\subsection{Failure Mode}

Failure mode of three K-joint specimens in each group is almost the same. Therefore, failure mode of one specimen in each group is analyzed herein. Figure 12a-c show the deformation of specimen UPL-1. The U-shape connector is severely deformed. However, no separation between the U-shape connector and the SHS members is observed. Besides, all the screws are sound. The maximum deformed region of the $\mathrm{U}$-shape connector is circled in Figure 12b. In addition, chord local plastification is observed as shown in Figure 12c.

Figure 13a-c show the deformation of specimen UPU-1. The U-shape connector is also severely deformed. Moreover, no separation between the U-shape connector and the SHS members is observed, and all the screws are sound. The maximum deformed region of the U-shape connector is circled in Figure 13b. Moreover, chord local plastification is observed as shown in Figure 13c. 


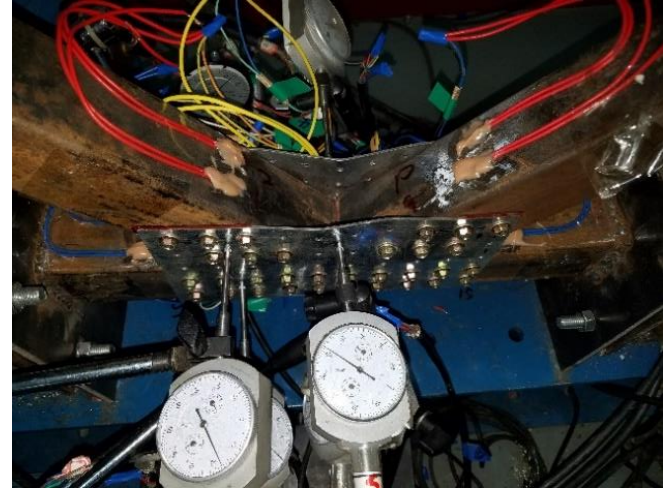

(a) Top view 1 .

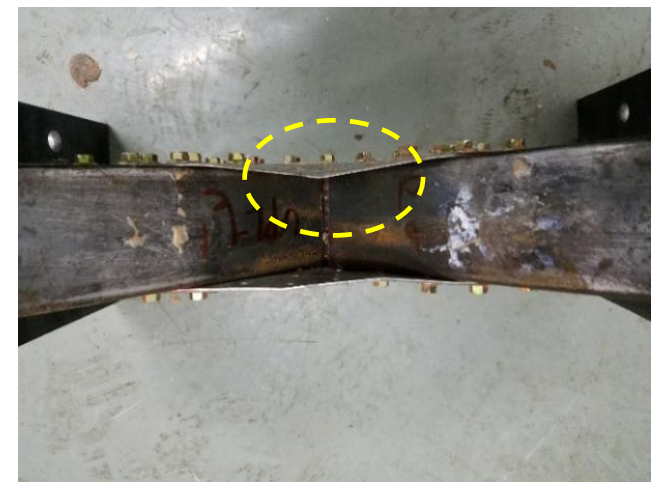

(b) Top view 2 .

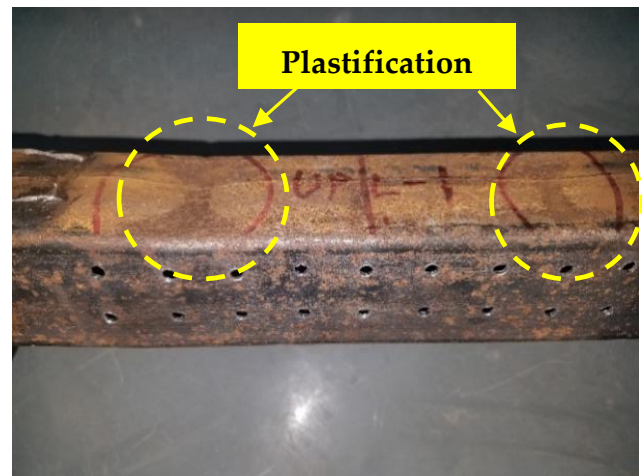

(c) Chord plastification.

Figure 12. Deformation of the specimen UPL-1.

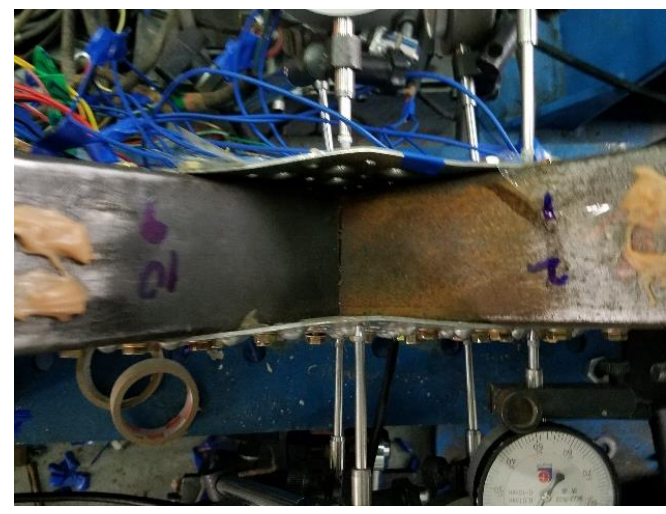

(a) Top view 1 .

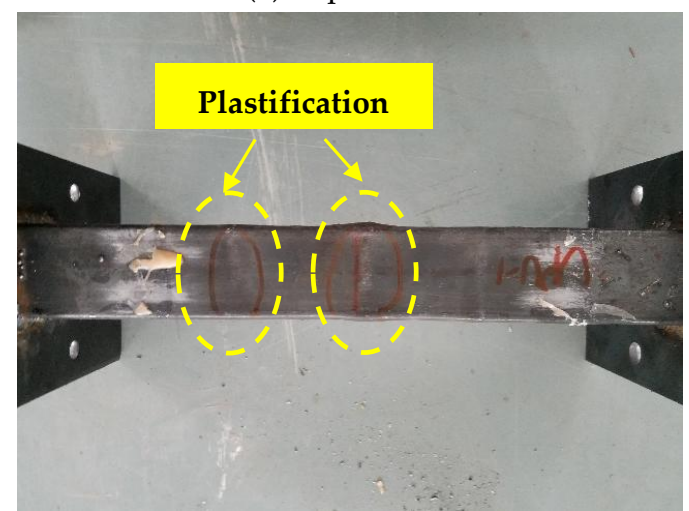

(c) Chord plastification.

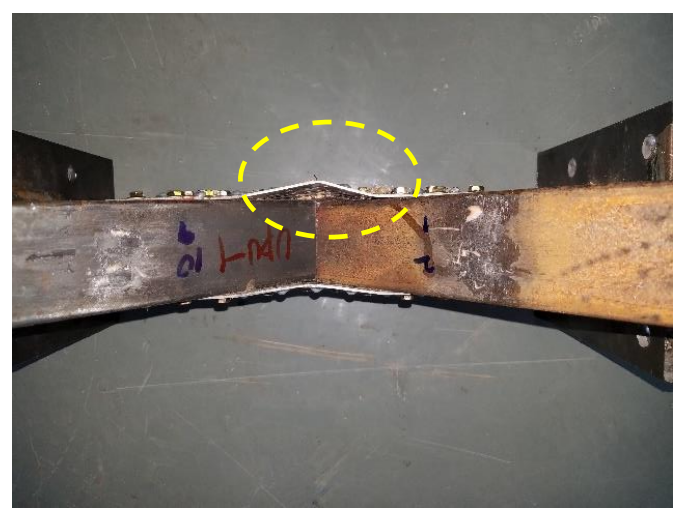

(b) Top view 2 .

Figure 13. Deformation of specimen UPU-1. 
Figure 14a-c show the deformation of specimen ULW-1. Large deformation is also observed on the U-shape connector. Moreover, no separation between the U-shape connector and the SHS members is observed, and all the screws are sound. The maximum deformed region of the U-shape connector is circled in Figure 14b. Moreover, chord local plastification is observed as shown in Figure 14c.

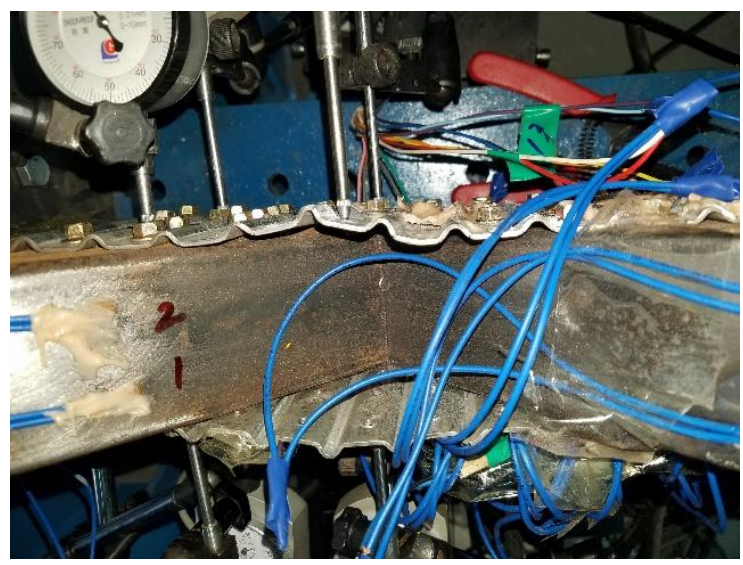

(a) Top view 1 .

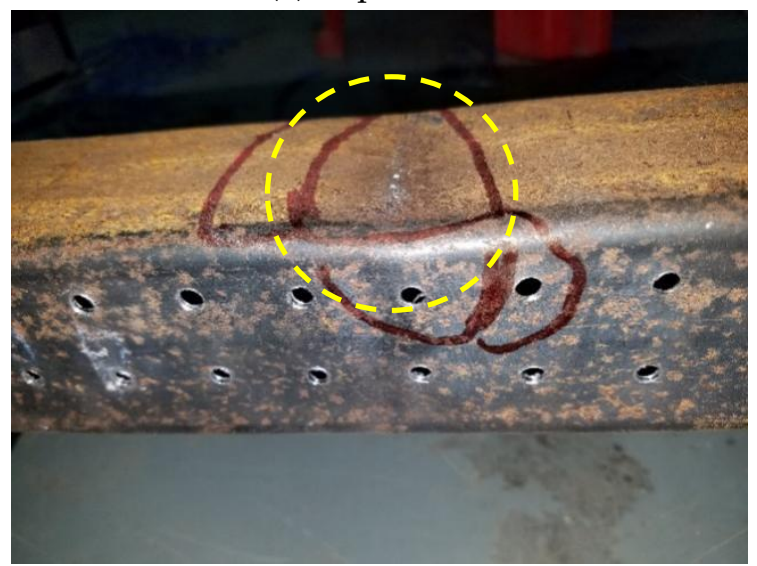

(c) Chord plastification.

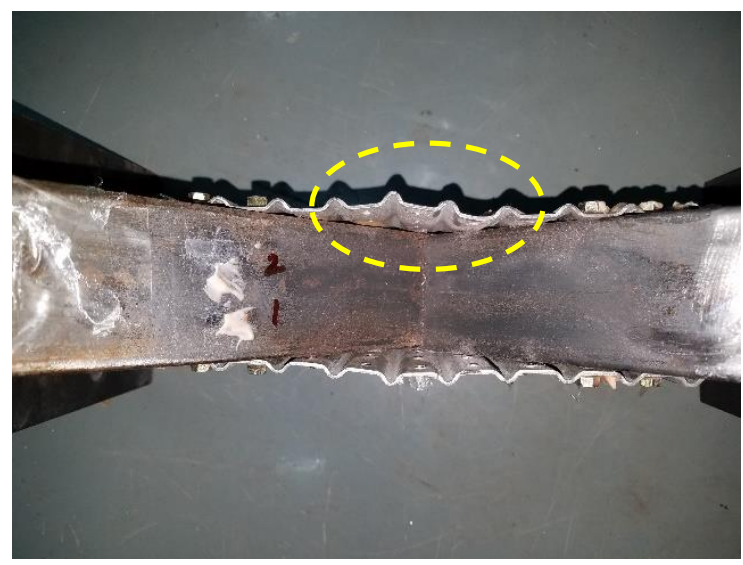

(b) Top view 2 .

Figure 14. Deformation of specimen ULW-1.

Figure $15 \mathrm{a}-\mathrm{c}$ show the deformation of specimen UTW-1. Deformation of the U-shape connector is not very obvious and no separation between the U-shape connector and the SHS members is observed; besides, all the screws are sound. Moreover, chord local plastification is observed at the joint region as shown in Figure 15c. Different from all the specimens in the other three groups, chord local plastification also occurs at the region circled in red in Figure 15c due to the combination action of shear and bending at the chord end.

In summary, for all the 12 specimens tested, large deformation of the U-shape connector is observed. Besides, chord local plastification occurs at the region where the braces contact the chord. Therefore, it can be concluded that joint failure is governed by both the deformation of the U-shape connector and the chord local plastification. In addition, no separation between the U-shape connector and the SHS members is observed, and no damage is found for all the screws. Different from all the specimens in group 1-3, chord local plastification also occurs at the region near to the chord end due to the combination action of shear and bending for specimens in group 4. 


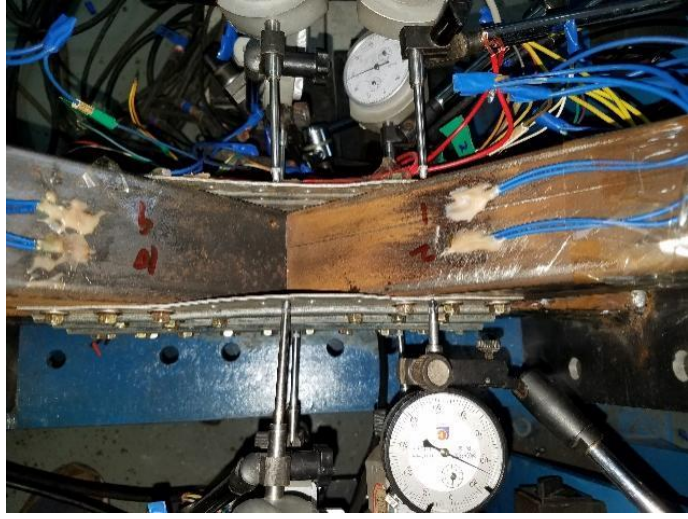

(a) Top view 1 .

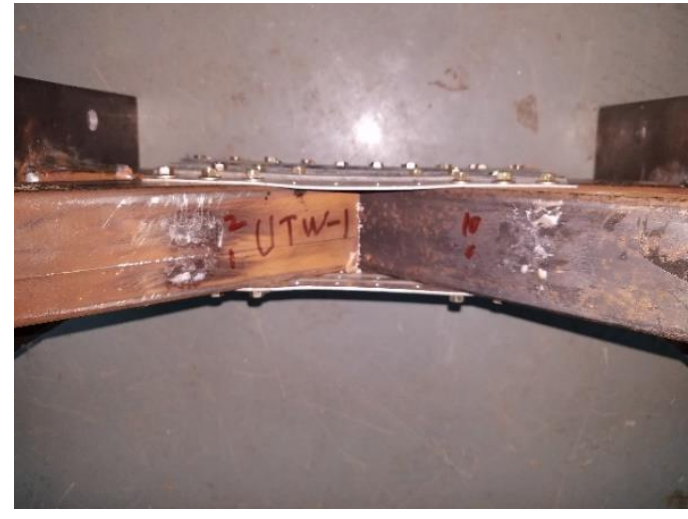

(b) Top view 2 .

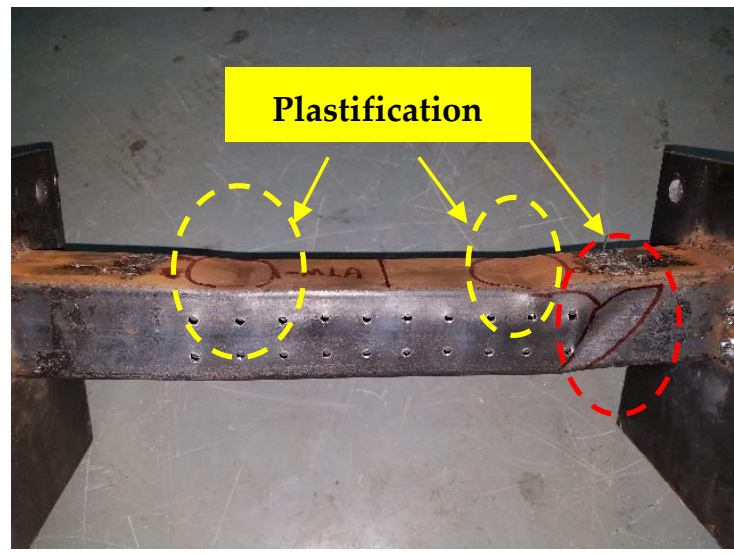

(c) Chord side view 2 .

Figure 15. Deformation of specimen UTW-1.

\subsection{Loading-Displacement Curves}

Loading-displacement curves of specimens in group 1 are shown in Figure 16a-c. Displacement in this study refers to the out-of-plane displacement of the U-shape connector. For the three specimens, the maximum displacement is from displacement transducer ' $7 \mathrm{~B}$ ' (refer to Figure 11) and is in between 4.7 and $9.5 \mathrm{~mm}$. Peak load of all loading-displacement curves is close.

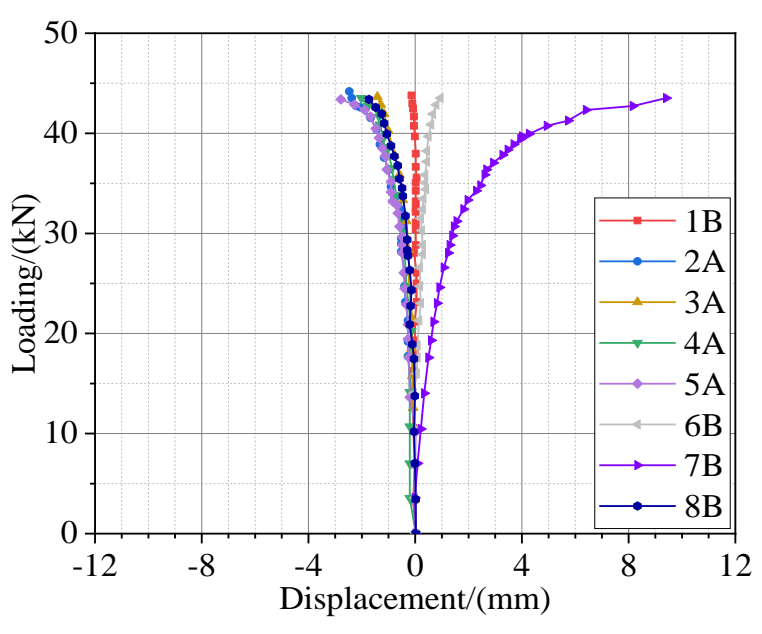

(a) UPL-1.

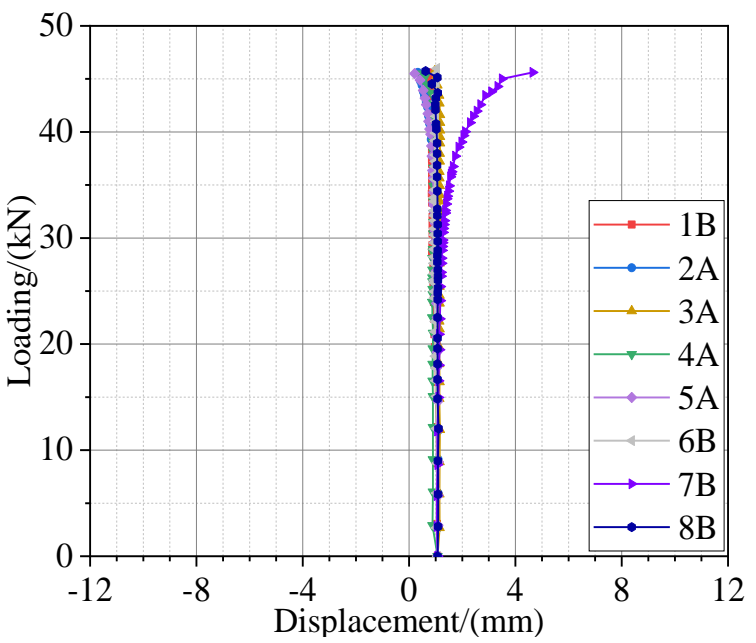

(b) UPL-2.

Figure 16. Cont. 


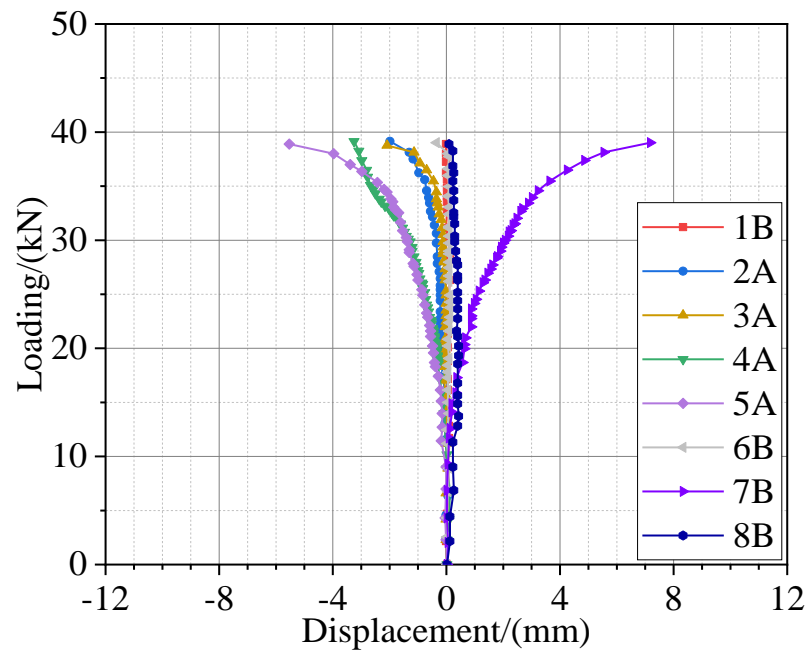

(c) UPL-3.

Figure 16. Loading-displacement curves of specimens in group 1.

Loading-displacement curves of specimens in group 2 are shown in Figure 17a-c. For specimen UPU-1, the maximum displacement is from displacement transducer ' $5 \mathrm{~A}^{\prime}$ ', while for specimens UPU-2 and UPU-3, the maximum displacement is also from displacement transducer '7B' (refer to Figure 11). The maximum displacement of three specimens is in between 3.8 and $11.2 \mathrm{~mm}$.

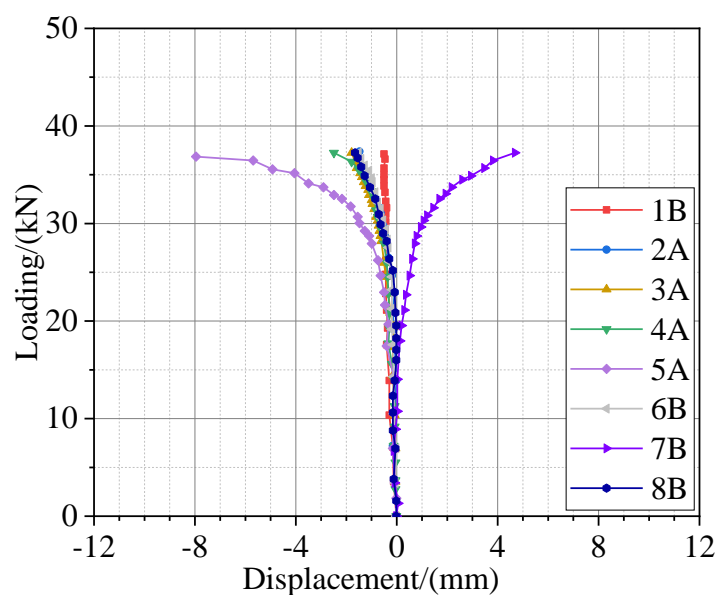

(a) UPU-1.

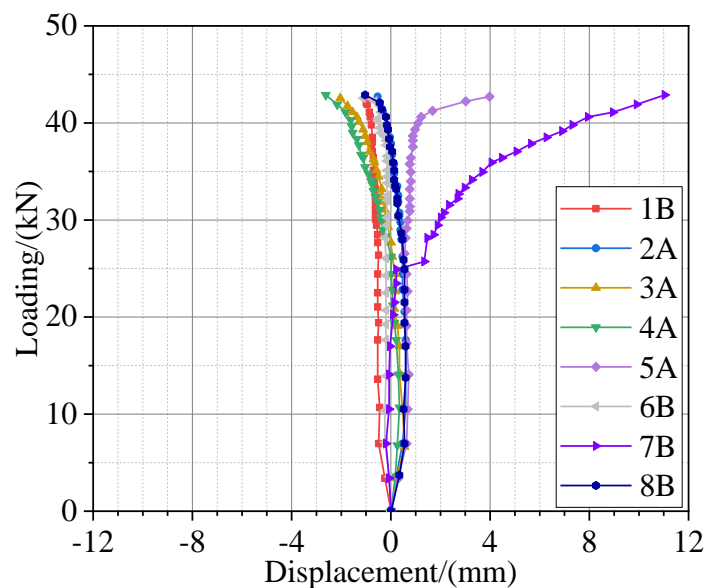

(b) UPU-2.

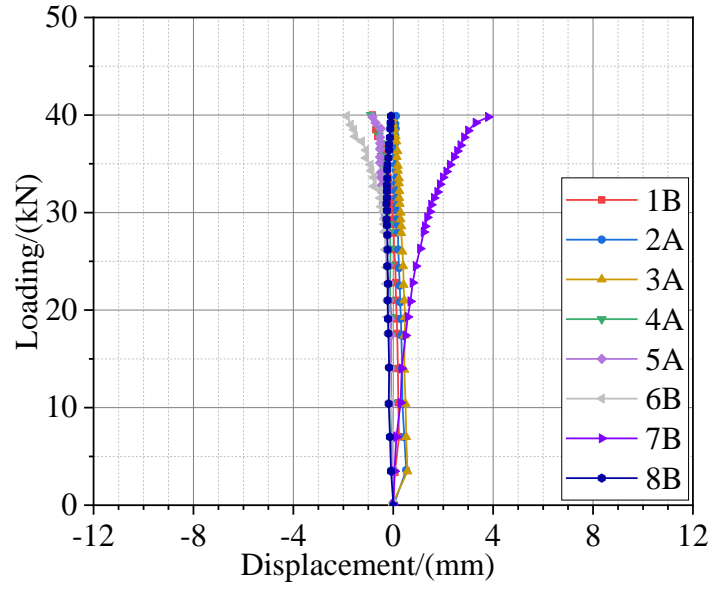

(c) UPU-3.

Figure 17. Loading-displacement curves of specimens in group 2. 
Loading-displacement curves of specimens in group 3 are shown in Figure 18a-c. For the three specimens, the maximum displacement is also from displacement transducer ' $7 \mathrm{~B}$ ' (refer to Figure 11) and is in between 5.6 and $9.5 \mathrm{~mm}$.

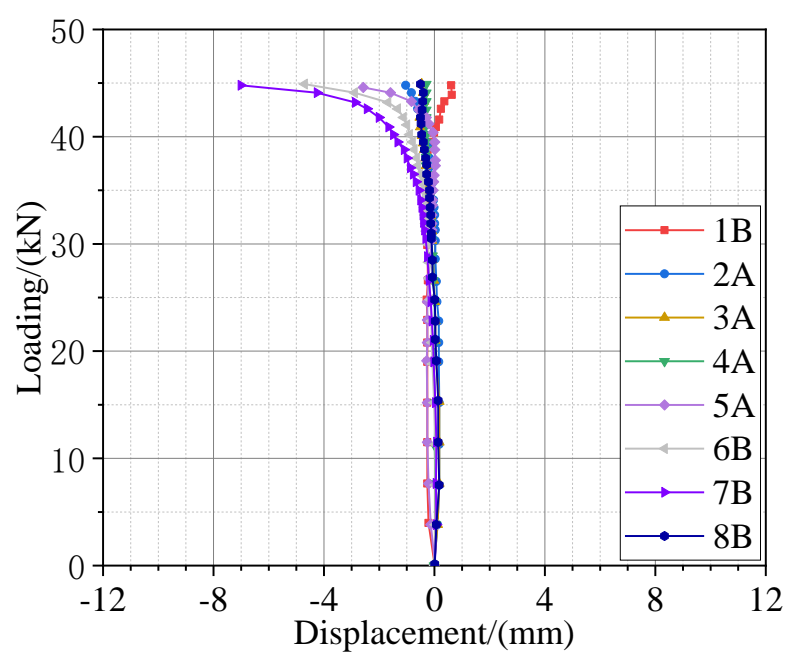

(a) ULW-1.

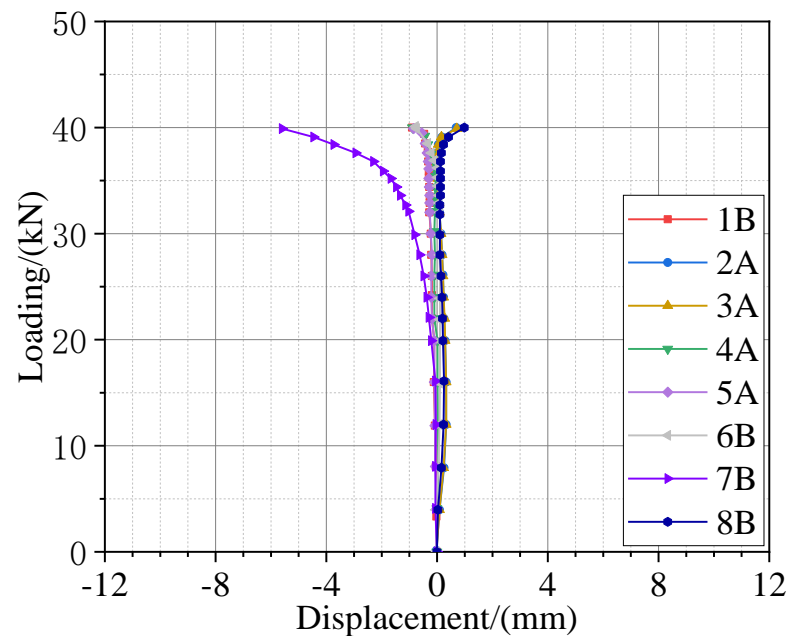

(b) ULW-2.

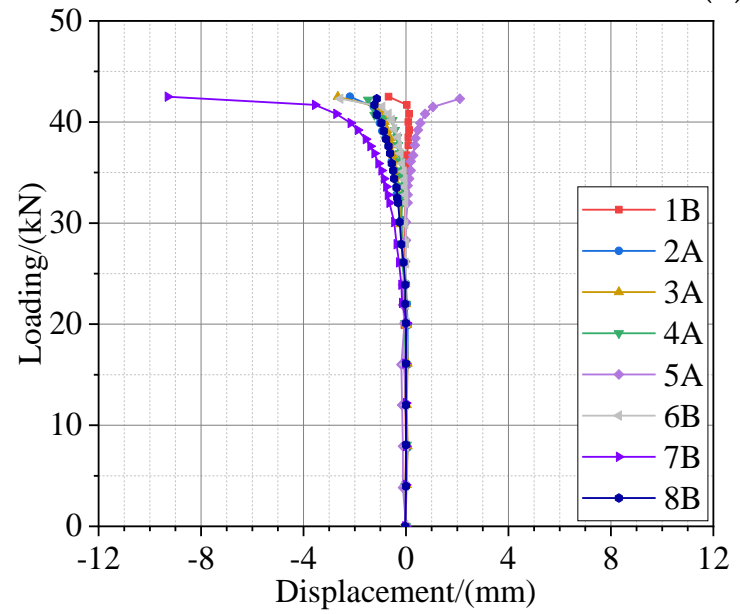

(c) ULW-3.

Figure 18. Loading-displacement curves of specimens in group 3.

Loading-displacement curves of specimens in group 4 are shown in Figure 19a-c. It can be seen that the maximum displacement is not at a fixed position. For the three specimens in group 4, out-of-plane displacement of the connector is much smaller compared to that in other specimens and is less than $3 \mathrm{~mm}$.

Overall, the ultimate bearing capacities of the $12 \mathrm{~K}$-joint specimens are close, within the range of $37.1-45.6 \mathrm{kN}$. It appears that the stamping indentation slightly affects the ultimate bearing capacity of the proposed K-joint. However, strip stamping grooves in the horizontal directions can significantly reduce the deformation of the U-shape connector. 


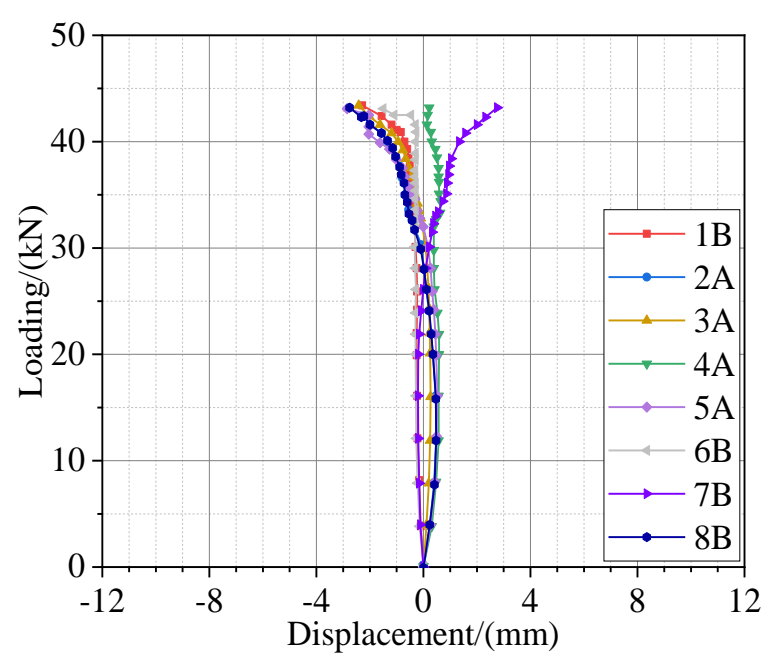

(a) UTW-1.

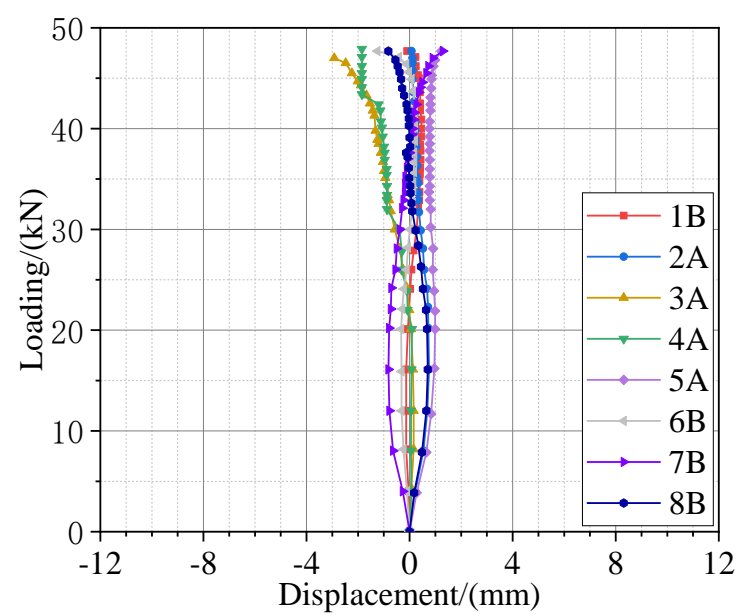

(b) UTW-2.

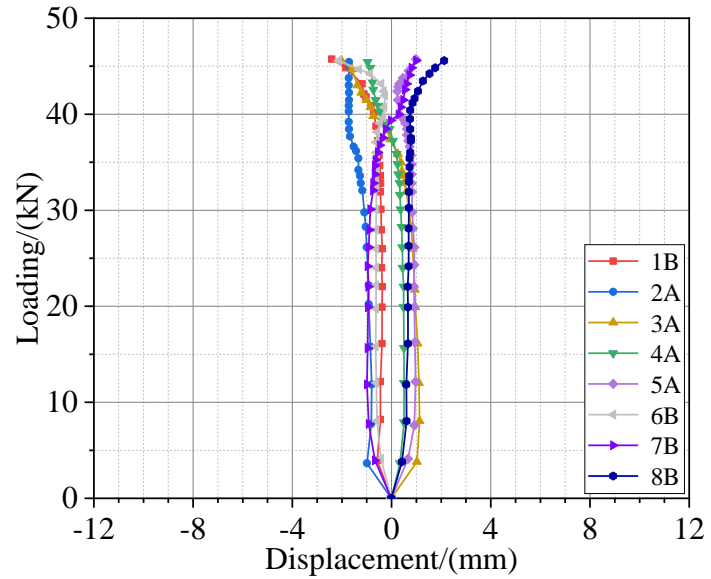

(c) UTW-3.

Figure 19. Loading-displacement curves of specimens in group 4.

\subsection{Ultimate Bearing Capacity}

The ultimate bearing capacity of each specimen is taken as the peak load of the corresponding loading-displacement curves shown in Section 4.2. The ultimate bearing capacity of three specimens in each group is not identical. This may be due to the fact that the thickness and strength of all the U-shape connectors are not exactly the same. Overall, the ultimate strength of three specimens in each group is close. The ultimate bearing capacities of the $12 \mathrm{~K}$-joint specimens are summarized in Table 3.

By making a comparison among the average of the ultimate bearing capacity of three specimens in each group, it can be concluded that the pattern of stamping indentation has a negligible effect (it causes a maximum $16.9 \%$ difference between specimen UTW-2 and UPL-3) on the ultimate bearing capacity of the K-joint. Comparing three specimens in group 1, specimens using the UTW connector have a higher average ultimate bearing capacity and other specimens using the ULW and UPU connectors have a lower average ultimate bearing capacity. This implies that the stamping indentation patterns used in the ULW and UPU connectors may have a negative effect on the ultimate bearing capacity of the proposed K-joint. In reality, the UTW connector is preferred for the proposed K-joint. 
Table 3. Ultimate bearing capacity of each specimen.

\begin{tabular}{ccccc}
\hline \multirow{2}{*}{$\begin{array}{c}\text { Group } \\
\text { No. }\end{array}$} & $\begin{array}{c}\text { Specimen } \\
\text { No. }\end{array}$ & $\begin{array}{c}\text { Thickness of } \\
\text { the Connector }\end{array}$ & $\begin{array}{c}\text { Ultimate Bearing } \\
\text { Capacity }\end{array}$ & The Average \\
\cline { 3 - 5 } & UPL1 & $\mathbf{( m m )}$ & $\mathbf{( k N )}$ & $\mathbf{( k N )}$ \\
\hline \multirow{2}{*}{ Group 1 } & UPL2 & 1.74 & 43.40 & \\
& UPL3 & 1.75 & 45.60 & 42.60 \\
\hline \multirow{2}{*}{ Group 2 } & UPU1 & 1.75 & 38.90 & \\
& UPU2 & 1.73 & 37.10 & \\
& UPU3 & 1.73 & 42.70 & \\
Group 3 & ULW1 & 1.75 & 39.90 & \\
& ULW2 & 1.77 & 44.80 & \\
\hline \multirow{2}{*}{ Group 4 } & ULW3 & 1.76 & 40.00 & 44.50 \\
& UTW1 & 1.75 & 42.40 & \\
\hline
\end{tabular}

\section{Finite Element Analyses of Specimens Using UTW Connector}

In this section, finite element (FE) parametric study is carried out on the K-joint using the UTW connector as it has the highest ultimate bearing capacity and minimum connector deformation. The effect of three key parameters, including chord stress ratio $n$, half widthto-thickness ratio of the chord $\gamma$ and brace-to-chord wall thickness ratio $\tau_{1}$, on the ultimate bearing capacity of the targeted K-joint is investigated.

\subsection{FE Modelling}

The FE model is created in ABAQUS software. Solid element C3D8R is used for the FE model. All the self-drilling screws are not modelled because they are sound in the test and tie the U-shape connector and the SHS members tightly during the whole testing. In order to model the interaction between the U-shape connector and the SHS members caused by the screws, a ring-shaped surface shown in Figure 20 is created on both the U-shape connector and the SHS members at the screw region. The two red surfaces are tied together in the FE modelling whereas hard contact with normal and tangential behavior is defined at other physical contact areas (blue surfaces in Figure 20) of the U-shape connector and SHS members. Because a surface cannot be defined as contact and tie interactions simultaneously in ABAQUS software, it has to create an untreated region (green surfaces in Figure 20) between the tied and contacted regions. Untreated surfaces in Figure 20 mean no contact or tie is defined between the two of them. Figure 21 shows a completed mesh model of a K-joint using the UTW connector and mesh density is increased for the connector.

Boundary conditions of the FE models are shown in Figure 22a,b. As shown in Figure 22a, for the FE models used for investigating the effect of chord stress ratio $n$, one end of the chord is fixed, and the other end is constrained only in X-and Y-directions so that axial force can be applied in Z-direction. For the free end of two braces, only axial displacement is allowed. For other FE models, two ends of the chord are fixed (no axial force applied to the chord), and also only axial displacement is allowed for the free end of two braces as shown in Figure 22b. A general static analysis has been run for each FE model in this study. For the brace axial loading, it is applied using the 'Risk' method in ABAQUS software. 


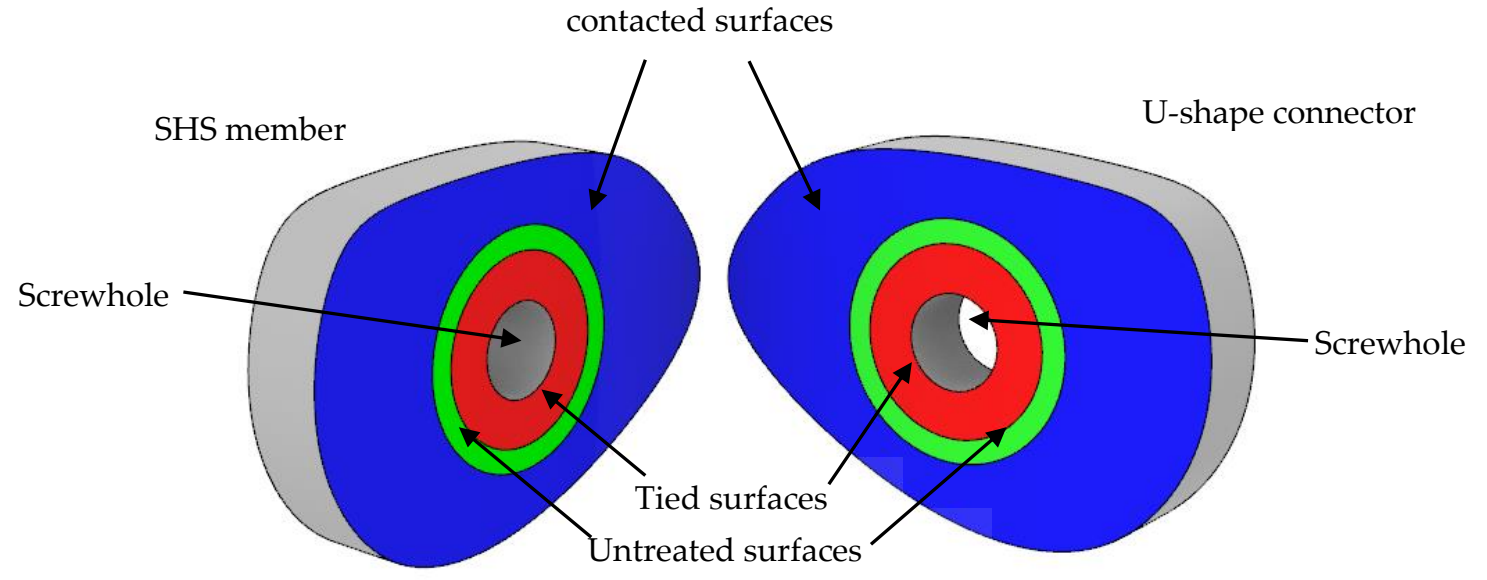

Figure 20. Illustration of interactions between the connector and the SHS member.

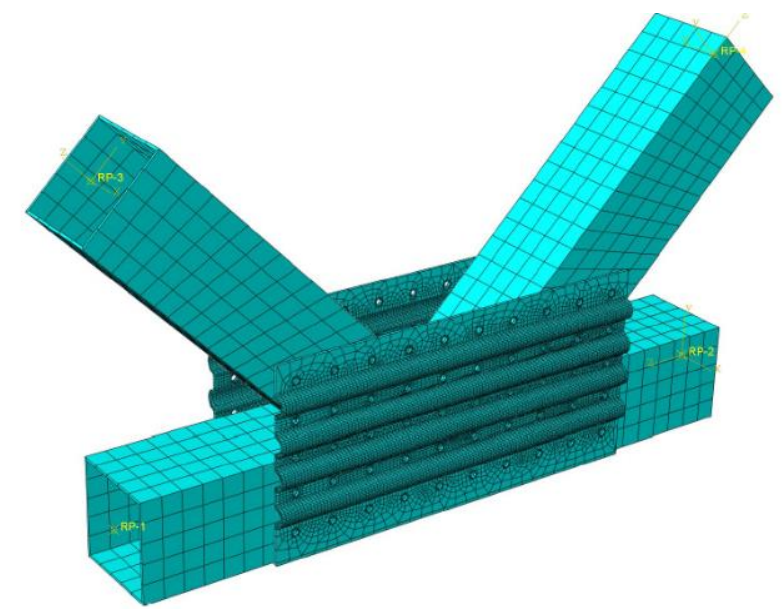

Figure 21. Mesh model of typical K-joint specimens using the UTW connector.

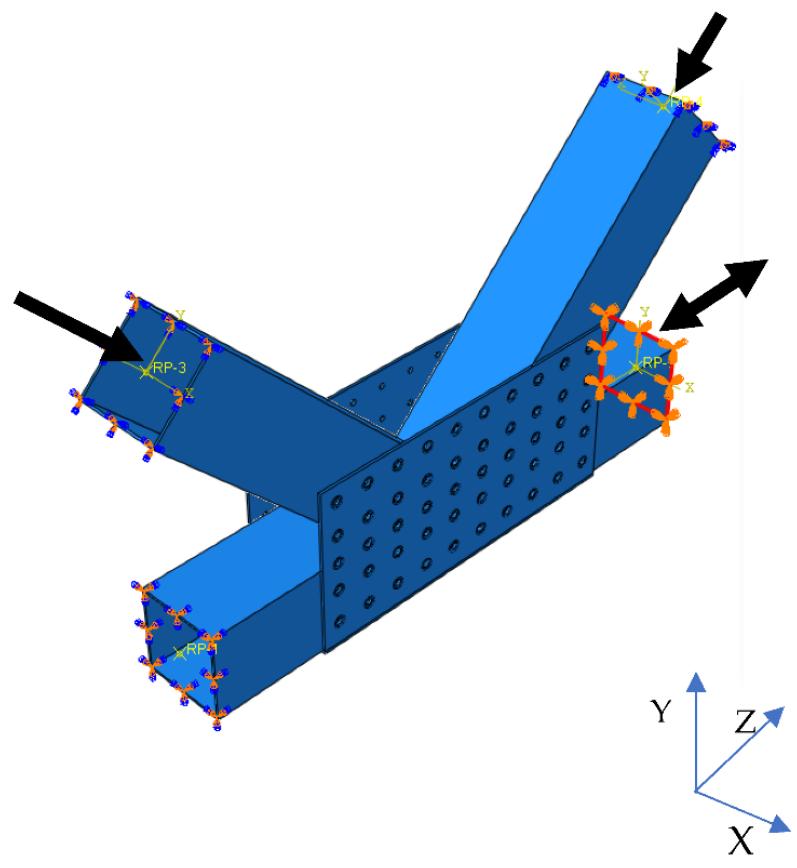

(a) $n \neq 0$.

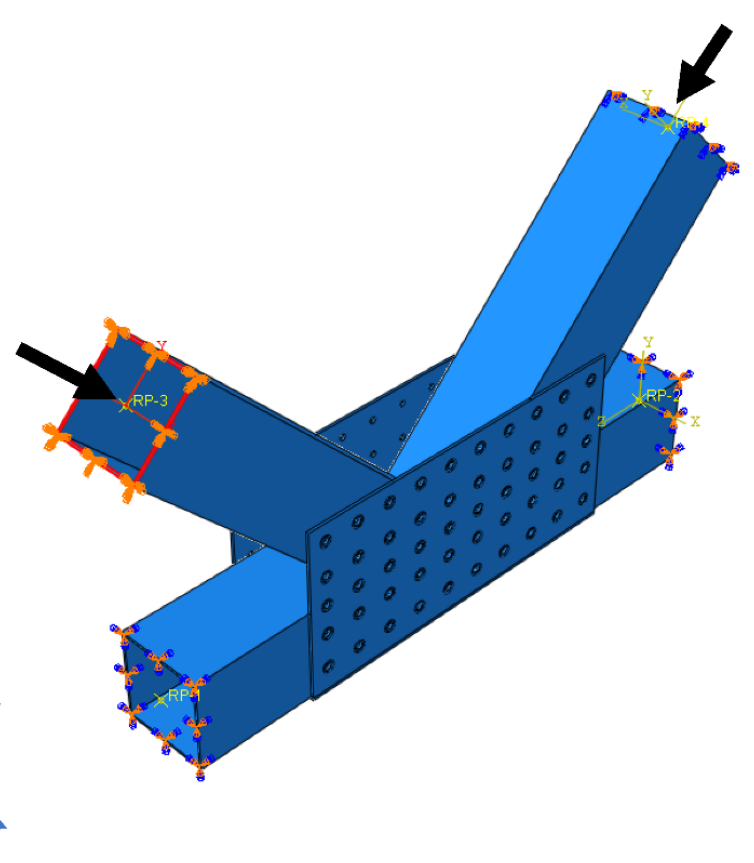

(b) $n=0$.

Figure 22. Boundary conditions of FE models. 


\subsection{Validation of FE Modelling}

Figure 23a-c show the comparison of loading-displacement curves of three specimens including UTW-1, UTW-2 and UTW-3. Displacement for the experimental curve in this section refers to the value obtained from the displacement transducer ' $7 \mathrm{~B}^{\prime}$ (refer to Figure 11). It can be seen that accuracy of the FE modelling in this study is acceptable.

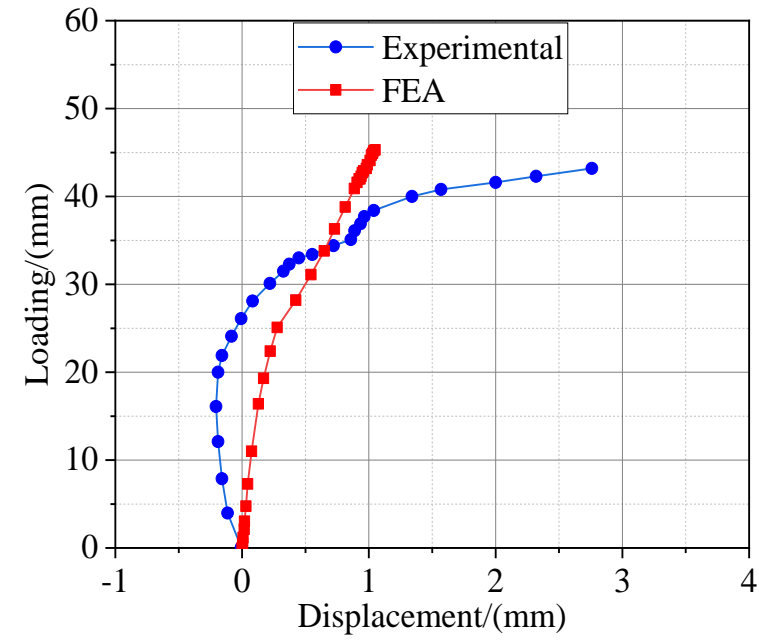

(a) UTW-1.

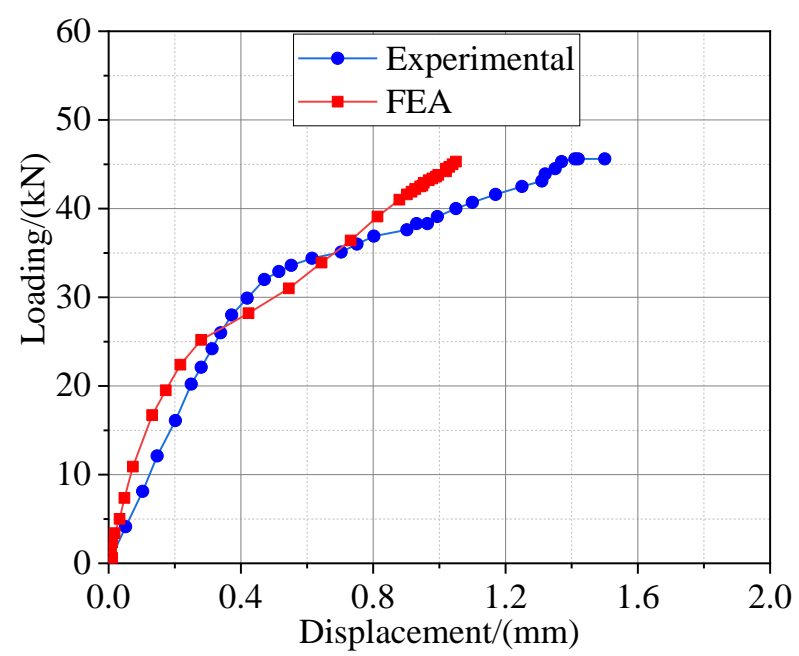

(b) UTW-2.

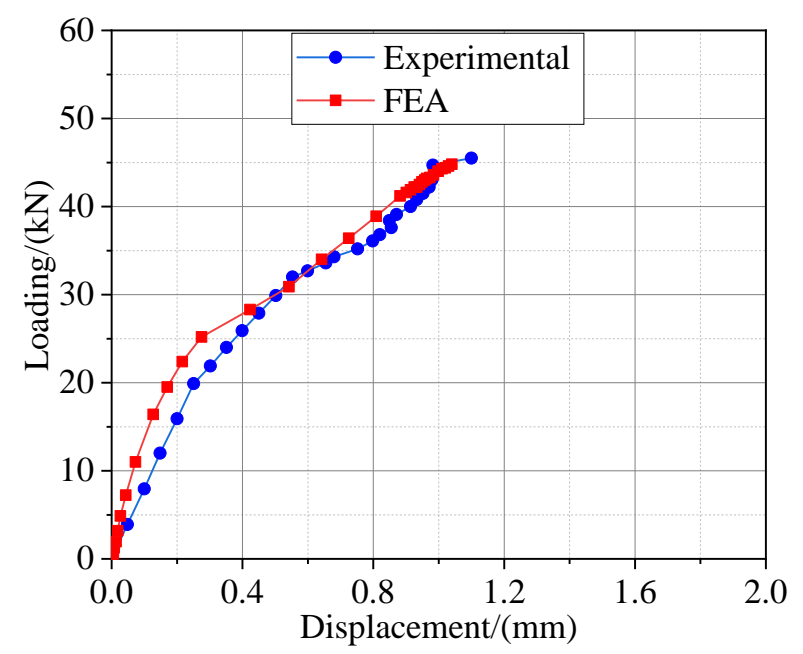

(c) UTW-3.

Figure 23. Comparison of loading-displacement curves.

Figure 24a,b show the deformation of the U-shape connector and the displacement contour of the chord of the FE model UTW-1, respectively. It can be seen that deformation of the U-shape connector is small, similar to the observation in the test (Figure 15a,b). For the chord in the FEA, large local displacement (circled in black) can be observed at the region where the brace is connected to the chord. It is also the same as the observation in the test (Figure 15c). 


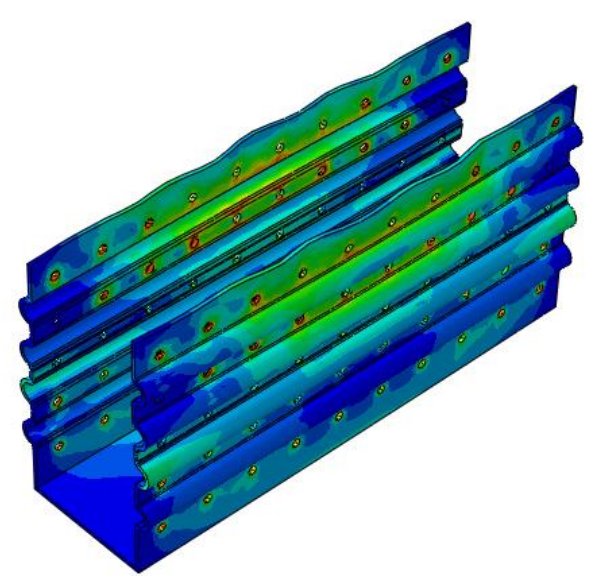

(a) U-shape connector.

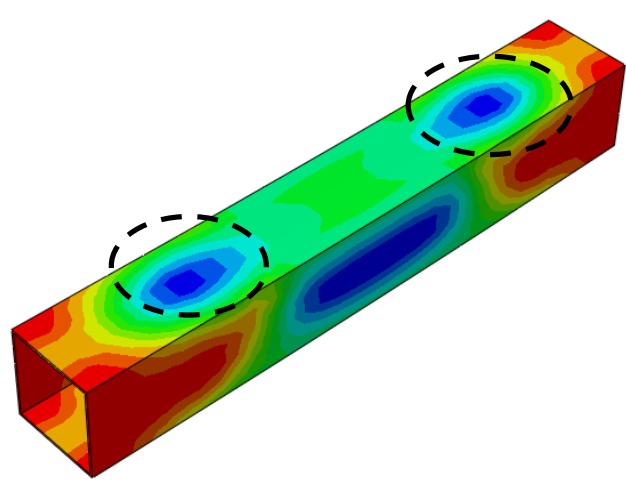

(b) The chord.

Figure 24. Deformation of the U-shape connector and displacement contour of the chord of FE model UTW-1.

\subsection{Parametric Study}

A total of $27 \mathrm{~K}$-joint models using the UTW connector have been investigated. Dimensionless parameters of each model and the corresponding ultimate bearing capacity are summarized in Table 4 . The ultimate bearing capacity values in Table 4 are defined as the peak value of the loading-displacement curves obtained from FEA.

Table 4. Details of the FE models investigated.

\begin{tabular}{ccccc}
\hline No. & $\boldsymbol{\gamma}$ & $\boldsymbol{\tau}_{\mathbf{1}}$ & $\boldsymbol{n}$ & Ultimate Bearing Capacity (kN) \\
\hline 1 & 15 & 1.0 & -0.6 & 38.2 \\
2 & 15 & 1.0 & -0.4 & 34.1 \\
3 & 15 & 1.0 & -0.2 & 38.2 \\
4 & 15 & 1.0 & 0.0 & 47.9 \\
5 & 15 & 1.0 & 0.2 & 21.8 \\
6 & 15 & 1.0 & 0.4 & 17.4 \\
7 & 15 & 1.0 & 0.6 & 15.5 \\
8 & 20 & 1.0 & -0.6 & 28.7 \\
9 & 20 & 1.0 & -0.4 & 26.4 \\
10 & 20 & 1.0 & -0.2 & 33.5 \\
11 & 20 & 1.0 & 0.0 & 45.0 \\
12 & 20 & 1.0 & 0.2 & 25.0 \\
13 & 20 & 1.0 & 0.4 & 20.8 \\
14 & 20 & 1.0 & 0.6 & 19.1 \\
15 & 30 & 1.0 & -0.6 & 17.5 \\
16 & 30 & 1.0 & -0.4 & 19.2 \\
17 & 30 & 1.0 & -0.2 & 21.0 \\
18 & 30 & 1.0 & 0.0 & 31.0 \\
19 & 30 & 1.0 & 0.2 & 20.4 \\
20 & 30 & 1.0 & 0.4 & 16.2 \\
21 & 30 & 1.0 & 0.6 & 15.3 \\
22 & 15 & 1.0 & 0.0 & 47.9 \\
23 & 25 & 1.0 & 0.0 & 33.2 \\
24 & 30 & 1.0 & 0.0 & 31.0 \\
25 & 20 & 1.2 & 0.0 & 46.2 \\
26 & 20 & 1.4 & 0.0 & 48.0 \\
27 & 20 & 1.6 & 0.0 & 51.1 \\
\hline
\end{tabular}

Chord axial stresses, including the compression and the tension, have a significant effect on the ultimate bearing capacity of welded tubular joints $[1,23,24]$. Therefore, it is also necessary to investigate the effect of chord axial stresses on the proposed K-joint. 
Parameter $n$ is defined as the ratio of the applied chord axial stress to the chord yield stress. Negative and positive values of $n$ mean that the chord is under axial compression and tension, respectively. Figure 25 shows the effect of $n$ on the ultimate bearing capacity of the proposed K-joints. It can be seen that the ultimate bearing capacity of the K-joint generally decreases as the chord axial tension stress increases from 0 to $0.6 n$. For the FE models with $\gamma$ is 15 and 20 under chord axial compression, the ultimate bearing capacity firstly decreases and then increases a little. For the FE models with $\gamma$ is 30, the ultimate bearing capacity decreases as chord axial tension stress increases.

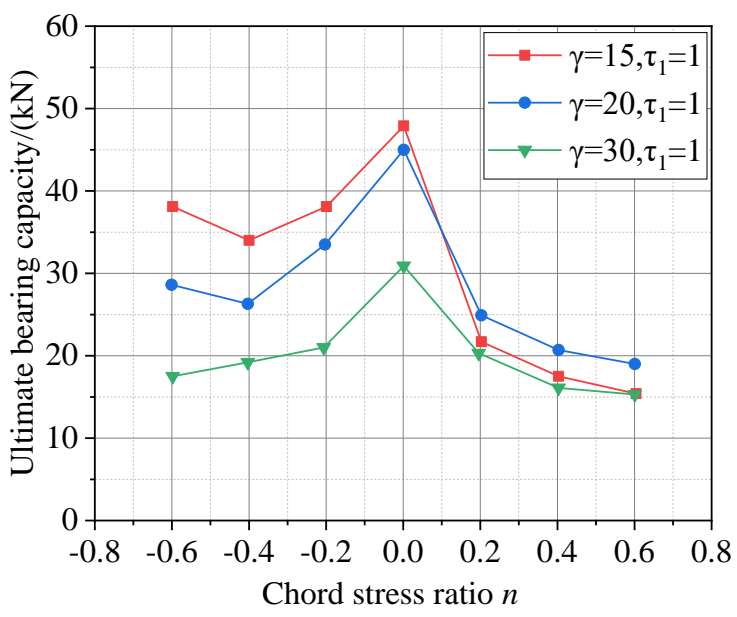

Figure 25. Effect of $n$.

Figure 26 shows the effect of half width-to-thickness ratio of the chord $\gamma$ on the ultimate bearing capacity of the K-joint investigated. It can be seen that the ultimate bearing capacity of the K-joint decreases as $\gamma$ increases, the same as the welded tubular joints [1].

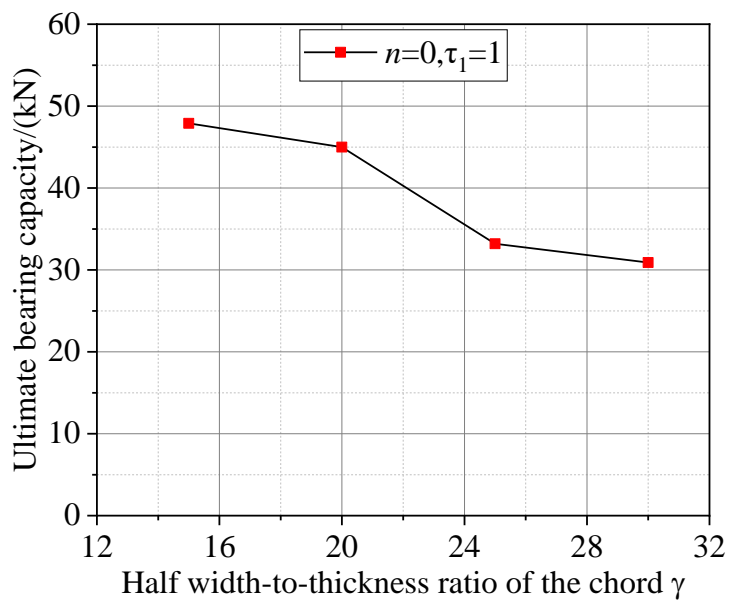

Figure 26. Effect of $\gamma$.

Figure 27 shows the effect of brace-to-chord wall thickness ratio $\tau_{1}$ on the ultimate bearing capacity of the K-joint investigated. It can be seen that the ultimate bearing capacity of the K-joint increases as $\tau_{1}$ increases; in other words, increasing the brace thickness can enhance the ultimate bearing capacity of the K-joint when the chord section is fixed. 


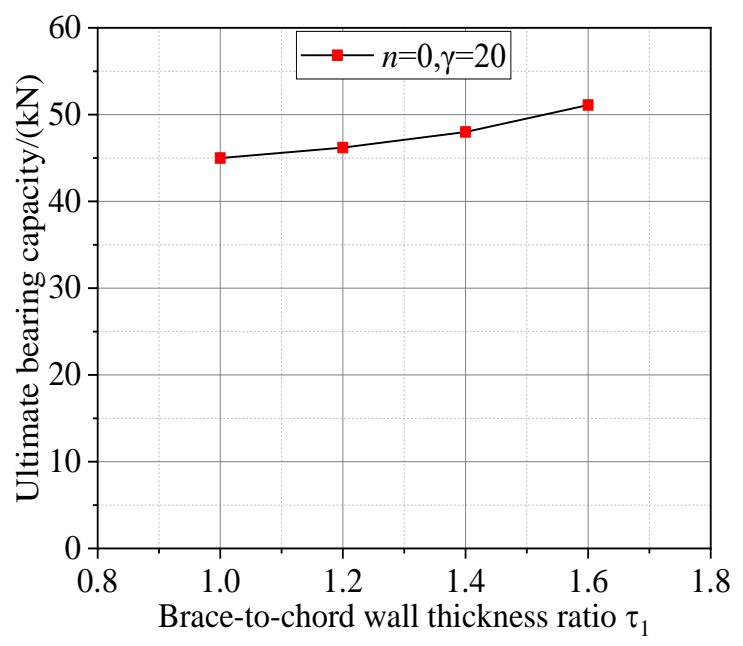

Figure 27. Effect of $\tau_{1}$.

\section{Conclusions}

This study aims to investigate the ultimate bearing capacity of a novel K-joint consisting of thin-walled SHS members, a U-shape connector and self-drilling screws, and the effect of three patterns of stamping indentation fabricated on the U-shape connector on the ultimate bearing capacity of the proposed K-joint. A total of 12 specimens were tested to failure under monotonic brace axial compressive loading. Failure mode and the ultimate bearing capacity of each specimen have been analyzed. Finally, finite element analyses were carried out to study the effect of three key parameters, including chord stress ratio, chord radius-to-thickness ratio and brace-to-chord thickness ratio, on the ultimate bearing capacity of proposed K-joints using the UTW connector. Based on the testing and FE results in the present study, the conclusion below may be drawn:

(1) Through investigating all K-joint specimens, it can be concluded that joint failure is governed by both the deformation of the U-shape connector and the chord local plastification. Besides, the U-shape connector and the wall of SHS members keep in contact tightly during the testing for all the specimens, and all the screws are sound.

(2) Some patterns of stamping indentation fabricated on the U-shape connector may bring an unfavorable effect to the ultimate bearing capacity of the proposed K-joint, such as the stamping pits (UPU connector). For all the specimens investigated, those with the UTW connector, i.e., connectors with strip stamping grooves in the horizontal direction, generally have a higher ultimate bearing capacity and a much smaller connector deformation.

(3) Similar to the welded SHS joints, chord axial stresses, including the compression and the tension, can significantly reduce the ultimate bearing capacity of the proposed $\mathrm{K}$-joint using the UTW connector. Moreover, a larger half width-to-thickness ratio of the chord $\gamma$ will result in a smaller ultimate bearing capacity of the proposed K-joint using the UTW connector.

(4) The ultimate bearing capacity of the K-joint using the UTW connector increases with the brace-to-chord wall thickness ratio $\tau_{1}$ when the chord section is fixed.

Author Contributions: Conceptualization, X.W.; software, X.Y.; investigation, H.Z.; writing—original draft preparation, T.L.; writing—review and editing, X.W.; supervision, Y.Y.; project administration, Y.L. and X.G.; All authors have read and agreed to the published version of the manuscript.

Funding: This study was funded by the National Key Research and Development Program of China (2017YFC0703702) and Major Technical Innovation Projects of Hubei Province (2018ACA131).

Institutional Review Board Statement: Not applicable.

Informed Consent Statement: Not applicable. 
Data Availability Statement: The data used to support the findings of this study are available from the corresponding author upon request.

Acknowledgments: The authors express their great gratitude towards the Structural Test Center of Wuhan University of Technology. The authors also appreciate all assistance from the master students in the research team during the testing and simulation processes.

Conflicts of Interest: The authors declare that they have no conflict of interest.

\section{Nomenclature}

$\gamma \quad$ Half width-to-thickness ratio of the chord

$\tau_{1} \quad$ Brace-to-chord wall thickness ratio

$n \quad$ Chord stress divided by chord yield stress

\section{References}

1. Wardenier, J.; Paker, J.A.; Zhao, X.L.; van der Vegte, G.J. Hollow Sections in Structural Applications; CIDECT: Geneva, Switzerland, 2010.

2. Mills, J.; LaBoube, R. Self-drilling screw joints for cold-formed channel portal frames. ASCE J. Struct. Eng. 2004, 130, 1799-1806. [CrossRef]

3. Lee, Y.H.; Tan, C.S.; Mohammad, S. Review on cold-formed steel connections. Sci. World J. 2014, 2014, 951216. [CrossRef] [PubMed]

4. Yan, W.; Mu, T.; Xie, Z.; Yu, C. Experimental investigation of typical connections for fabricated cold-formed steel trusses. Adv. Struct. Eng. 2019, 22, 141-151. [CrossRef]

5. Li, Q.Y.; Young, B. Tests of cold-formed steel built-up open section members under eccentric compressive load. J. Constr. Steel Res. 2021, 184, 106775. [CrossRef]

6. Zou, Y.; Zhou, X.; Shi, Y. Shear resistance of cold-formed thin-walled steel inter-story connections. J. Constr. Steel Res. 2021, 183, 106757. [CrossRef]

7. Chen, X.; Blum, H.B.; Roy, K. Cold-formed steel portal frame moment-resisting joints: Behaviour, capacity and design. J. Constr. Steel Res. 2021, 183, 106718. [CrossRef]

8. Zaharia, R.; Dubia, D. Stiffness of joints in bolted connected cold-formed steel trusses. J. Constr. Steel Res. 2006, 62, 240-249. [CrossRef]

9. Öztürk, F.; Pul, S. Experimental and numerical study on a full scale apex connection of cold-formed steel portal frames. Thin Walled Struct. 2015, 94, 79-88. [CrossRef]

10. Pouladi, P.; Ronaldson, J.; Clifton, G.C. Finite-element assisted design of eaves joint of cold-formed steel portal frames having single channel sections. Structures 2019, 20, 452-464. [CrossRef]

11. Far, H.; Saleh, A.; Firouzianhaji, A. A simplified method to determine shear stiffness of thin-walled cold formed steel storage rack frames. J. Constr. Steel Res. 2017, 138, 799-805. [CrossRef]

12. Song, L.; Yan, W.; Yu, C. Flexural behavior investigation of the CFS truss beams with self-piercing riveted connection. J. Constr. Steel Res. 2019, 156, 28-45. [CrossRef]

13. Song, L.; Yan, W.; Zhang, X. Feasibility research on the application of self-piercing riveted connection in cold-formed steel structures. J. Constr. Steel Res. 2020, 168, 105957. [CrossRef]

14. Wang, J.F.; Wang, W.Q.; Xiao, Y.; Guo, L. Cyclic behavior tests and evaluation of CFS truss composite floors. J. Build. Eng. 2020, 35, 101974. [CrossRef]

15. Roy, K.; Lau, H.H.; Ting, T.C.H. Experiments and finite element modelling of screw pattern of self-drilling screw connections for high strength cold-formed steel. Thin-Walled Struct. 2019, 145, 106393. [CrossRef]

16. Fahmy, A.S.; Swelem, S.M.; Mussttaf, H.H. Beam-column connections behavior of cold-formed steel members: New experimental configuration. KSCE J. Civil Eng. 2020, 24, 2147-2159. [CrossRef]

17. Mathieson, C.; Roy, K.; Clifton, G.C. Failure mechanism and bearing capacity of cold-formed steel trusses with HRC connectors. Eng. Struct. 2019, 201, 109741. [CrossRef]

18. Dizdar, Ç.; Baran, E.; Topkaya, C. Strength and stiffness of floor trusses fabricated from cold-formed steel lipped channels. Eng. Struct. 2019, 181, 437-457. [CrossRef]

19. Phan, D.T.; Mojtabaei, S.M.; Hajirasouliha, I.H. Design and optimization of cold-formed steel sections in bolted moment connections considering bimoment. ASCE J. Struct. Eng. 2020, 146, 04020153. [CrossRef]

20. Zagórowska, M.G.; Galewska, E.U.; Deniziak, P. Experimental investigation of joint with positive eccentricity in CFS truss. Thin Walled Struct. 2020, 157, 106998. [CrossRef]

21. Gan, J.C.; Lim, J.H.; Lim, S.K.; Lin, H.S. Experimental and numerical study on the effect of heel plate length and thickness on the structural integrity of cold-formed steel roof trusses. Int. J. Steel Struct. 2021, 21, 22-34. [CrossRef]

22. Güldür, H.; Baran, E.; Topkaya, G. Experimental and numerical analysis of cold-formed steel floor trusses with concrete filled compression chord. Eng. Struct. 2021, 234, 111813. [CrossRef] 
23. Choo, Y.S.; Qian, X.D.; Wardenier, J. Effects of boundary conditions and chord stresses on static strength of thick-walled CHS K-joints. J. Constr. Steel Res. 2006, 62, 316-328. [CrossRef]

24. Li, T.; Lie, S.T.; Cong, P.W. Effect of chord axial stresses on the static strength of cracked tubular T/Y-joints under out-of-plane and in-plane bending. Adv. Struct. Eng. 2019, 22, 1698-1710. [CrossRef] 